\title{
Preliminary Evaluation of a Nuclear Scenario Involving Innovative Gas Cooled Reactors
}

\author{
Barbara Vezzoni, ${ }^{1}$ Nicola Cerullo, ${ }^{1,2}$ Giuseppe Forasassi, ${ }^{1}$ Emil Fridman, ${ }^{3}$ \\ Guglielmo Lomonaco, ${ }^{1,2}$ Vincenzo Romanello, ${ }^{4}$ and Eugene Shwageraus ${ }^{5}$ \\ ${ }^{1}$ Department of Mechanical, Nuclear and Production Engineering (DIMNP), University of Pisa, CIRTEN, \\ Largo L. Lazzarino No. 2, 56126 Pisa, Italy \\ ${ }^{2}$ Energy and Environmental Conditioning Department (DIPTEM), University of Genova, Via all'Opera Pia n. 15/a, \\ 16145 Genova, Italy \\ ${ }^{3}$ Accident Analysis Division (FWSS), Forschungszentrum Dresden-Rossendorf (FZD), P.O. Box 5101 19, 01314 Dresden, Germany \\ ${ }^{4}$ Institute for Nuclear and Energy Technologies (IKET), Karlsruhe Institute for Tecnology (KIT), Hermann-von-Helmholtz-Platz 1, \\ 76344 Eggenstein, Leopoldshafen, Germany \\ ${ }^{5}$ Department of Nuclear Engineering, Ben Gurion University of the Negev, P.O. Box 653, Beer Sheva 84105, Israel
}

Correspondence should be addressed to Nicola Cerullo, cerullo@docenti.ing.unipi.it

Received 31 March 2009; Accepted 1 September 2009

Recommended by Jim Kuijper

In order to guarantee a sustainable supply of future energy demand without compromising the environment, some actions for a substantial reduction of $\mathrm{CO}_{2}$ emissions are nowadays deeply analysed. One of them is the improvement of the nuclear energy use. In this framework, innovative gas-cooled reactors (both thermal and fast) seem to be very attractive from the electricity production point of view and for the potential industrial use along the high temperature processes (e.g., $\mathrm{H}_{2}$ production by steam reforming or I-S process). This work focuses on a preliminary (and conservative) evaluation of possible advantages that a symbiotic cycle (EPRPBMR-GCFR) could entail, with special regard to the reduction of the HLW inventory and the optimization of the exploitation of the fuel resources. The comparison between the symbiotic cycle chosen and the reference one (once-through scenario, i.e., EPRSNF directly disposed) shows a reduction of the time needed to reach a fixed reference level from $\sim 170000$ years to $\sim 1550$ years (comparable with typical human times and for this reason more acceptable by the public opinion). In addition, this cycle enables to have a more efficient use of resources involved: the total electric energy produced becomes equal to $\sim 630 \mathrm{TWh} / \mathrm{year}$ (instead of only $\sim 530 \mathrm{TWh}$ /year using only EPR) without consuming additional raw materials.

Copyright ( 2009 Barbara Vezzoni et al. This is an open access article distributed under the Creative Commons Attribution License, which permits unrestricted use, distribution, and reproduction in any medium, provided the original work is properly cited.

\section{Introduction}

The fossil fuels extensive use for the energy production is, nowadays, no longer sustainable. Therefore new innovative strategies for the energy sector have to be found.

Focusing on the electricity production sector, central role could be entrusted to the nuclear energy production, because it is the only source of energy able to provide a large quantity of energy without greenhouse gas releases (or with very small quantity if the whole nuclear energy chain is taken into account) [1].

The present work focuses on the analysis of a possible symbiotic cycle linking European Pressurized Reactors
(EPRs) with Pebble Bed Modular Reactors (PBMRs) and Gen-IV Gas Cooled Fast Reactors (GCFRs).

In particular, the advantages concerning the final wastes minimization and the exploitation of the fuel resources involved have been compared with a chosen reference scenario (the Once-through scenario). The investigation of these two aspects is in agreement also with the Gen-IV sustainability goals [2].

One of the major questions that public opinion asks to nuclear community is: how the nuclear fuel cycle could be closed?

Worldwide, some strategies have been indicated and the most agreed is the adoption of a geological disposal 
in synergy with the development of new facilities able to minimize during their life the produced wastes (e.g., using fast fission processes).

The present work is inserted in this framework. Gas cooled reactors adoption (thermal and fast solutions) has been analyzed, because these facilities seem to be very attractive for the future primary energy supply (not only for electricity chain), as consequence of the potential flexibility for a coupling with industrial high temperature processes.

In addition the innovative gas cooled reactors (HTRs and GCFRs) have some features (e.g., neutron economy) that seem to be particularly useful in order to minimize the long-term waste radiotoxicity and to improve the fuel exploitation.

\section{General Aspects}

The strong reliance on fossil fuels ( $83 \%$ of total energy supply and $66 \%$ of total electricity production [3]) has originated some social and environmental problems.

In fact, the geological distribution of fossil fuels involves only few countries that, in the most of the cases, do not have a stable political situation. This implies that the future supply could not be guaranteed a priori on the basis of the fossil fuels availability only. In addition, the extensive use of fossil fuels has involved an increase of greenhouse gas (GHG) emissions with effects on the world average energy temperature respect the preindustrial level [4].

Concerning nuclear energy resources, the situation is quite different, because Uranium is more homogeneously spread than oil, and in general in politically stable countries (e.g., Canada or Australia), so it is possible to be more confident for the future supply, considering also that nuclear energy has very low greenhouse gas emission rates (even if we look at the whole life cycle).

Even if the whole scientific community is not unanimous in this approach, the problem of climate change has motivated research activities at different level in several organizations. The Intergovernmental Panel on Climate Change (IPCC) has affirmed that the only way to arrest this warming process is to tangibly reduce the $\mathrm{CO}_{2}$ emissions before 2050 (where the desirable level is between $85 \%$ and $50 \%$ of actual releases) [4].

Taking into account this technical information, the G8 Heiligendamm Summit (2007) has fixed the value at 50\% of reduction in 2050 to achieve by the change of energyelectricity production chains [5], sector responsible for a very large fraction of $\mathrm{CO}_{2}$ emissions.

In order to reach, as soon as possible, this goal EU has fixed some intermediate objectives (the so-called $3 \times 20$ objectives) up to 2020: $20 \%$ of GHG emissions reduction achievable by the improvement of $20 \%$ of energy saving and the extension up to $20 \%$ of the renewable sources in the total energy mix [6].

In this framework, the worldwide agreement is essential, in fact some actions, nowadays deeply analysed, have been identified [7]:

(i) the improvement of energy efficiency in every sectors, (ii) the extensive use of renewable sources (hydro, biomass, wind, and solar),

(iii) the improvement on nuclear energy production and on new carbon capture and sequestration (CCS) technologies.

This work focus on the analysis of the nuclear energy role considering the advantages coming from the introduction of new facilities (e.g., Gas cooled reactors proposed within GenIV frame) $[1,8]$.

In addition, the social acceptability of nuclear energy has been considered as a base criterion to develop a new energy strategy; therefore solutions, as symbiotic cycle, with the aim to minimize final radioactive wastes (in particular Minor Actinides-MAs and High Level Waste) by the recycling of Plutonium and the transmutation of MAs (Am and $\mathrm{Np}$ ) became more and more attractive.

\section{Uranium Resources}

From the sustainability point of view, particular attention has to be directed to the optimization of the resources involved in a specific scenario.

As a matter of fact, Gen-IV reactors will not be ready before 2040 and till this date nuclear reactors will be Uranium consuming type (considering Gen-II reactors, and Gen-III and Gen-III ${ }^{+}$facilities). As a consequence, the analysis of resources is a basilar aspect to treat.

Therefore, the main question concerning resources could be [9]: will the Uranium resources be sufficient to cover the growth of reactor capacity, required to follow the energyelectricity demand?

The answer to this question is not easy because it depends on several different factors. Anyhow, scenario analysis could be a useful "tool" for this investigation. As presented in [10], the Identified Resources (available at cost $<130$ USD $/ \mathrm{kgU}$ ) are estimated at $5.469 \cdot 10^{6}$ tonU, where $3.338 \cdot 10^{6}$ tonU are Reasonably Assured Resources (RARs) and $2.13 \cdot 10^{6}$ tonU are Inferred Resources (IRs). At which could be added 2.8 million of tonU as prognosticate undiscovered resources, 22 million of tonU in phosphates and $6.078 \cdot 10^{6}$ tonTh (fertile fuel that could be used in nuclear reactors, e.g., HTR).

These values are only the boundaries for the scenario analysis, in fact a more interesting comparison is between the $\mathrm{U}$ annual production versus the $\mathrm{U}$ annual demand.

The total U annual demand in 2007 (407 reactors in operation worldwide) has been 69110 tonU; whereas the $\mathrm{U}$ annual production in 2007 has been 43328 tonU; this means that each year, to cover the demand, the stock pile of Uranium (collected during the previous years of nuclear energy use) is driven down [10]. In fact, as presented in Figure 1, starting from 1990 the uranium requirements are larger than the uranium production; therefore a correct and integrated strategy, starting from the $\mathrm{U}$ mines, has to be pursued.

A more complex situation seems to happen if the projections up to 2030 proposed by the IEA [11] will be realized. In fact, considering both the HIGH and LOW energy demand cases proposed, the nuclear capacity installed 


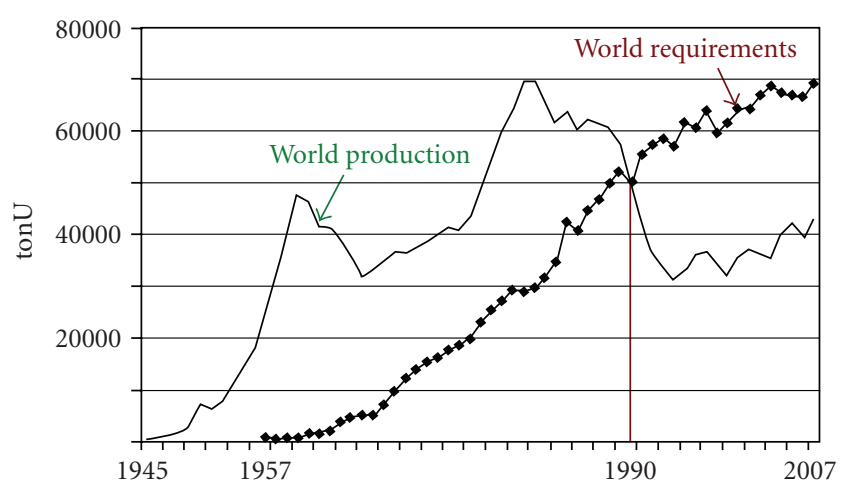

Figure 1: Historical data on Uranium World requirements and production [10].

worldwide will pass from $370 \mathrm{GWe}$ net to $509 \mathrm{GWe}$ and 663 GWe, respectively, that means in 2030 the Uranium requirements will be 93775 tonU/year in the LOW case and 121955 tonU/year in the HIGH case (of course the projections change considerably from region to region [10]). Starting from these considerations the Uranium resources $(<130 \$ / \mathrm{kgU}$ considering also the IR) could be sufficient to cover the demand only up to 2050 [9] and for the future needs only the introduction of fast reactors (perhaps in addition with new $U$ resources discovered) will be the only solution to adopt.

\section{Future Energy Demand}

In this work, the European situation has been analyzed considering a LOW and a HIGH energy envelopes, where the nuclear energy share in the period 2008-2050 has been evaluated.

The International Organizations (such as IPCC, IEA, IAEA), working in the energy scenario sector, have analysed the problem in a multidisciplinary way using complex models, where economical, political, and environmental considerations are taken into account simultaneously [4, $5,11]$. Data used in this paper is coming from the IAEA publications $[3,5,12]$.

Starting from the actual situation (130 reactors in the Western Europe for 884 TWh [13], 19180 tonU/year [10]), in order to evaluate the energy demand in 2050, some rates for the HIGH and the LOW estimates have been furnished and shown in Table 1.

With regard to electricity and nuclear production, the annual rates for the LOW scenario are, respectively, $+1 \%$ and $-2.2 \%$, while for the HIGH scenario these are $+2.8 \%$ and $+0.9 \%$, as presented in Table 1 .

Under these conditions Europe will pass from $884 \mathrm{TWh} /$ year in 2007 to $1356 \mathrm{TWh} /$ year (LOW case) or $2898.4 \mathrm{TWh} /$ year (HIGH case) that means a substantial increase in few years. This implies that without nuclear energy it will be impossible to cover the energy needs. On the other hand, the only use of nuclear energy will not be sufficient and the adoption of an integrated energy mix is a central point to analyse, too.
TABLE 1: Annual growth rates for Western Europe [3, 13].

\begin{tabular}{lccc}
\hline Parameter & \multicolumn{3}{c}{ Annual rates } \\
& LOW & HIGH \\
\hline Period & & $2008-2050$ \\
Population & $\sim 0.2 \%$ & \\
Primary energy & $+0.2 \%$ & & $+0.9 \%$ \\
Electric energy & $+1.0 \%$ & & $+2.8 \%$ \\
Nuclear capacity & $-2.2 \%$ & & $+0.9 \%$ \\
\hline
\end{tabular}

The World situation is even more significant (because it takes into account developing countries such as China and India). In this case the production in 2007 has been $2608 \mathrm{TWh} /$ year and the projections up to 2050 are [12] $5858.6 \mathrm{TWh} /$ year for the case LOW (annual rate of 1.9\%) and $10534 \mathrm{TWh} /$ year for HIGH case (annual rate 3.3\%).

Therefore, in this context, the search of the best solutions for the nuclear fleet (fuel cycles and different facilities) is a central point for the future nuclear development process, taking into account that also the $\mathrm{U}$ resources are not unlimited.

The analysis of fuel cycle, where evolutionary reactors (such as EPR) are inserted for the medium term and innovative reactors, HTR and GCFR, are used to reach the equilibrium condition will be very useful also for the decision making process.

In particular, HTR has several fundamental characteristics features, which distinguish them from other types of reactors and provide significant operational advantages.

First of all, the fuel is in the form of small ceramic coated particles, able to reach very high temperature operation and material burnup. In addition, the moderator is solid graphite and the coolant is neutronically and chemically inert helium.

Furthermore, HTRs are able to accommodate a wide variety of mixtures of fissile and fertile materials without any significant modifications of the core design, that enables to reach an ultra-high discharge burn-up ( $>750 \mathrm{GWd} / \mathrm{tHM})$.

This is useful from the resource utilization point of view (complete plutonium fission in a single step minimizes the proliferation risk in the use of this fuel form) and the high temperature reached by the cooling gas, Helium, $\left(>900^{\circ} \mathrm{C}\right)$ could be used not only for the electricity production but also for various industrial process, such as Hydrogen production by steam reforming or I-S process $[14,15]$.

\section{Symbiotic Cycle Investigated: EPR-PBMR-GCFR}

A preliminary investigation of the advantage that a symbiotic cycle could give, in order to minimize the radioactive wastes and to save U resources, has been performed.

A symbiotic fuel cycle is a strategically planned chain, where the output of a reactor is the input of the following. Each link of such a chain is a different kind of reactors, because each one is able to perform a different task. Of course, between two different steps, the fuel has to be cooled and reprocessed. 

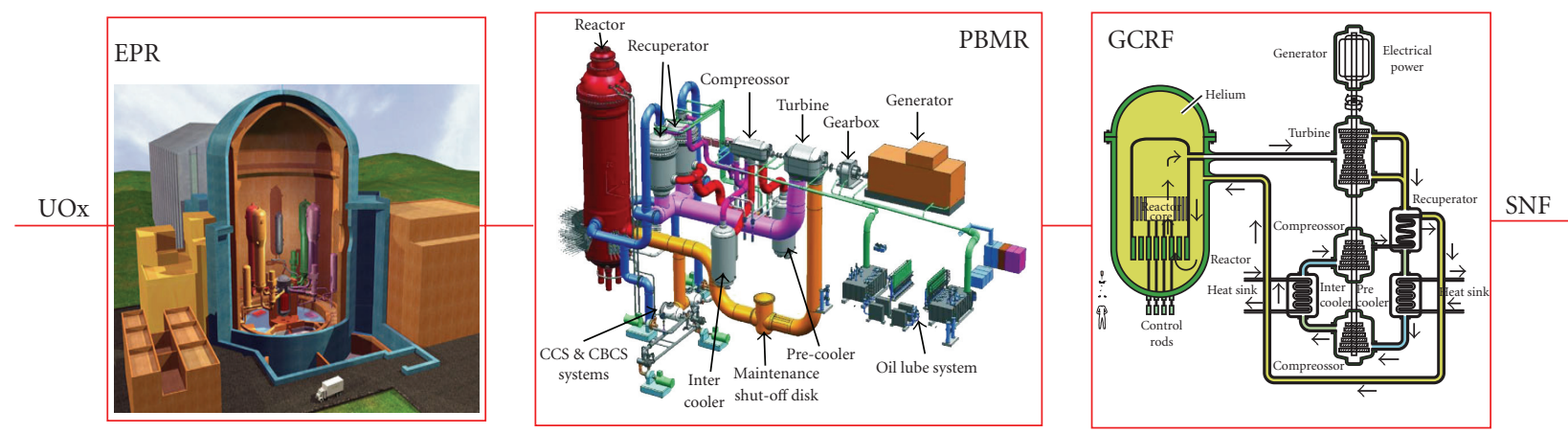

FIGURE 2: The symbiotic cycle investigated: EPR-PBMR-GCFR.

The symbiotic cycle investigated is presented in Figure 2, where the discharged fuel from EPR is inserted in an HTR (a PBMR has been adopted in this analysis) and after the irradiation it is inserted into the GCFR. The analyzed cycle was already considered in the previous papers [16-18].

Of course for a correct approach respecting reprocessing strategy, the time between the spent fuel extraction from the first facility and the introduction of new fuel in the second one has to be taken into account in synergy with the isotopic composition changes during this period. Because the performed analysis has to be considered as a first preliminary investigation, this issue has been, as a first approximation, neglected.

The simplified models adopted for each reactor are described briefly in the following parts.

In the past, several fuel cycles involving HTR have been studied $[14,18]$, where the comparison of merits and drawbacks of all solutions has been analyzed. In particular, different HTR compositions (high U enrichment -83\%and $\mathrm{Th}$, low $\mathrm{U}$ enrichment $-5 \%$ to $12 \%$-, medium $\mathrm{U}$ enrichment $-20 \%$ - and Th, only $\mathrm{Pu}$ content) could be analysed. In this case, the HTRs have been considered loaded only with reactor grade $\mathrm{Pu}$, further activities will be directed to investigate other fuel compositions.

For this preliminary activity, as presented later on, the symbiotic cycle chosen has been compared with the once-through strategy, such as the direct disposal of the SNF coming from EPR (without adopting reprocessing and separation of $\mathrm{Pu}$ and MAs).

Finally, as a first preliminary approximation, k-eff $=1$ has been chosen as exit condition for all the calculations; of course an important and necessary improvement for the future calculations will be to estimate a realistic discharge burn-up for every reactor type taking into account the EPR multiple batch loading scheme, the PBMR continuous reloading, and so forth.

5.1. EPR Simulation. The European Pressurized Reactor (EPR) is an evolutionary PWR designed by AREVA-NP company. It is a four loop reactor with a thermal power of $4500 \mathrm{MW}_{\text {th }}\left(1600 \mathrm{MW}_{\mathrm{e}}\right)$ with significant safety improvements; in fact, redundancy and diversification of the Emergency Safety Features-ESF (4 loops) enable to reduce the core
TABLE 2: Isotopic composition of EPR fuel (weight fraction).

\begin{tabular}{lccc}
\hline \multicolumn{4}{c}{ Isotopic composition } \\
\hline Isotope & $\mathrm{g} / \mathrm{cm}^{3}$ & Isotope & $\mathrm{g} / \mathrm{cm}^{3}$ \\
$\mathrm{O}^{16}$ & $1.18551 \mathrm{E}-01$ & $\mathrm{U}^{235}$ & $3.79023 \mathrm{E}-02$ \\
$\mathrm{U}^{234}$ & $2.73249 \mathrm{E}-04$ & $\mathrm{U}^{238}$ & $8.43045 \mathrm{E}-01$ \\
\hline
\end{tabular}

damage frequency $(\mathrm{CDF})$ at $6.1 \cdot 10^{-7}$ reactor/year instead of the $5.1 \cdot 10^{-5}$ reactor/year of the present in operation LWRs.

This type of reactor is under construction in Europe (Flamanville-France and Olkiluoto-Finland) and also in UK where the possibility to built this kind of facility is under evaluation [19].

For the simulation of the symbiotic cycle some approximations were assumed in order to minimize calculation time without compromising the acceptability of the work.

A single fuel assembly has been simulated, and modeled taking into account the real length $(420 \mathrm{~cm})$ and adding reflective boundary conditions in the radial direction (Figures 3 and 4). To take into account the distribution of neutron flux in $Z$-direction, the fuel assembly modeled has been inserted in a coaxial cylinder $(c z)$ with a total height of $8400 \mathrm{~mm}$, filled by borated water, also in order to simulate the contribution of neutron reflection in $z$ direction of the borated water above and below the assembly. As a preliminary approximation, the real axial burnup distribution in the core has not been taken into account.

The fuel assembly is a $17 \times 17$ square lattice (made up of 265 fuel rods and 24 guide thimbles) and the core is composed of 241 assemblies organized into three regions at different enrichments (external dimensions of assembly are $21.4 \times 21.4 \mathrm{~cm})$.

In this preliminary and simplified model, the $U$ enrichment adopted is $4.3 \%$ in $\mathrm{U}^{235}$ (values in literature are between $4 \%$ and $5 \%$ ), the composition simulated is presented in Table 2. Main data, extrapolated from the preliminary safety report of the UK-EPR [19], are summarized in Table 3.

The irradiation period was simulated by BGCore burnup code [20], considering three subsequent irradiation cycles of 600 effective full power days (EFPDs) spaced out by a decay period of 30 days, necessary to take into account the reactor internal fuel cycle (three zones radial shuffling). 


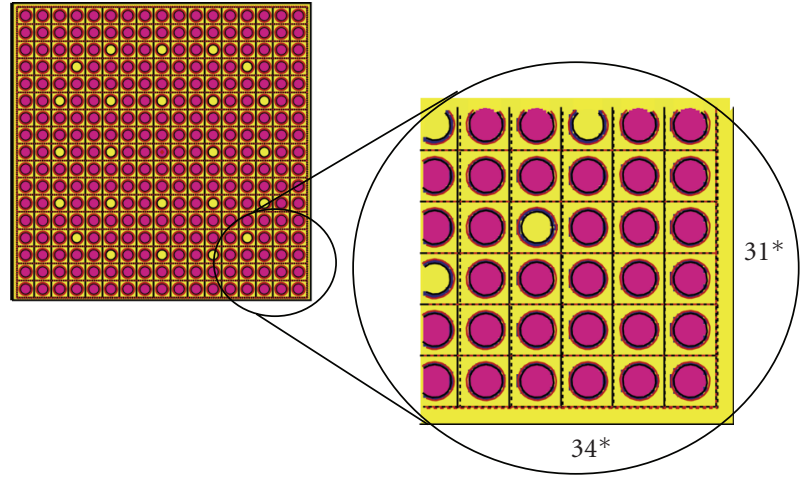

FIGURE 3: MCNP model of EPR fuel assembly: $x y$-section [19].

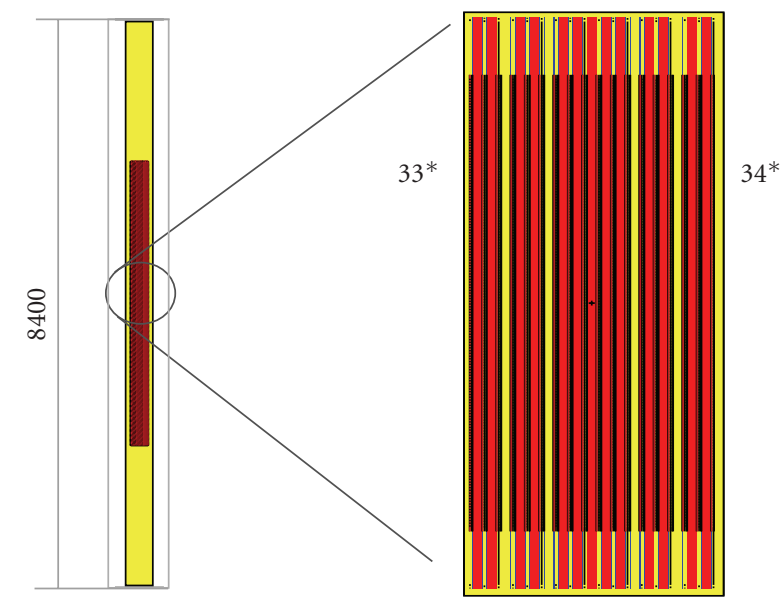

FIGURE 4: MCNP model of EPR fuel assembly: $x z$-section [19].

The behaviour of k-eff during the irradiation is shown in Figure 5, and additional details (burnup and std error) are summarized in Table 4. Of course, in our simplified model, the effect of radial leakage has been not directly taken into account.

Please note that the Xe effect has been "spread" (due to the chosen time steps) over the first 25 days (i.e., on the whole first time step).

In fact, on the basis of the composition evaluated after the burning in the EPR, the fuel composition for PBMR has been defined, as described in the following paragraph.

5.2. PBMR Simulation. In this preliminary version of symbiotic cycle, a PBMR loaded by $\mathrm{Pu}$ reactor grade has been simulated (the $\mathrm{Pu}$ and $\mathrm{Np}$ considered derived from the EPR modeled and described above). As known, the PBMR is a pebble-bed HTR.

HTRs are thermal reactors which are moderated by graphite and cooled by helium, where the chemical inertness of helium allows high coolant outlet temperatures (around $900^{\circ} \mathrm{C}$ ). That leads to very high thermal efficiencies (up to $50 \%)$ to be attained in electrical generation. This high temperature makes the HTR attractive also for other industrial applications different from the electricity production (e.g., the $\mathrm{H}_{2}$ production by steam-reforming or I-S).
TABLE 3: EPR parameters adopted for the model [19].

\begin{tabular}{lc}
\hline \multicolumn{2}{c}{ Reactor design parameters } \\
\hline Thermal power & $4500 \mathrm{MW}_{\mathrm{th}}$ \\
$\mathrm{N}^{\circ}$ of loops & 4 \\
Heat generated in fuel & $97.4 \%$ \\
Nominal pressure & $155 \mathrm{bar}$ \\
Thermal design flow rate/loop & $27195 \mathrm{~m}^{3} / \mathrm{h}$ \\
Ave. velocity along fuel rods & $4.8 \mathrm{~m} / \mathrm{s}$ \\
Nominal inlet temperature & $295.7^{\circ} \mathrm{C}$ \\
Ave. in core temperature & $313.7^{\circ} \mathrm{C}$ \\
Ave. in vessel temperature & $312.8^{\circ} \mathrm{C}$ \\
Ave. core heat flux & $54.7 \mathrm{~W} / \mathrm{cm}{ }^{2}$ \\
Ave. linear power density & $163.4 \mathrm{~W} / \mathrm{cm}$ \\
\hline \multicolumn{1}{c}{ Fuel assembly (dimensions given at $\left.20^{\circ} \mathrm{C}\right)$} \\
\hline Rod array & $17 \times 17$ \\
$\mathrm{~N}^{\circ}$ assembly & 241 \\
Fuel rods/assembly & 265 \\
Fuel assembly pitch & $21.504 \mathrm{~cm}$ \\
Fuel assembly length & $480 \mathrm{~cm}$ \\
Lattice rod pitch & $1.26 \mathrm{~cm}$ \\
Overall transverse dimensions & $21.4 \times 21.4 \mathrm{~cm}$ \\
Guide thimbles/assembly & 24 \\
\hline & \\
\hline Number & 63865 \\
Outside diameter & $9.50 \mathrm{~mm}$ \\
Diametrical gap & $0.17 \mathrm{~mm}$ \\
Pellet diameter & $0.57 \mathrm{~mm}$ \\
\hline & $8.19 \mathrm{~mm}$ \\
\hline
\end{tabular}

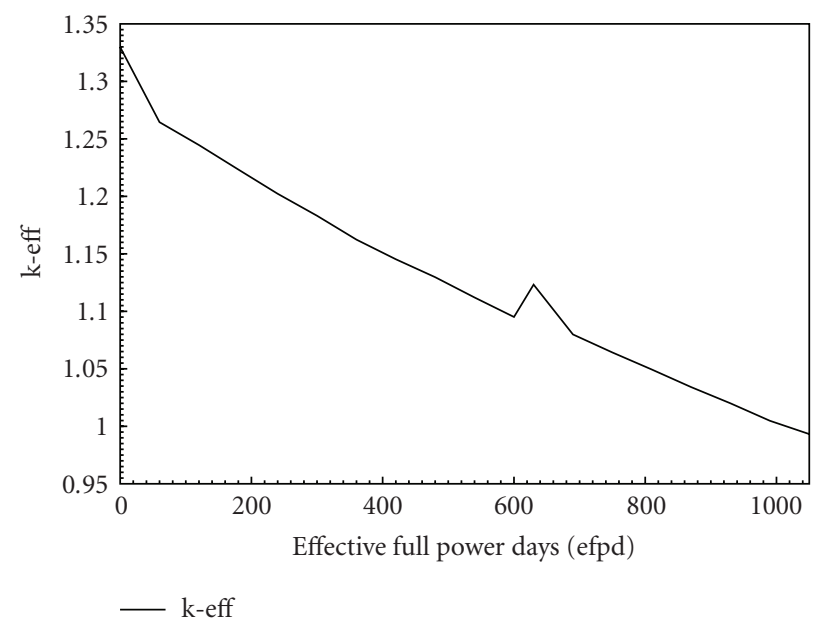

FIGURE 5: EPR simplified model: k-eff trend during irradiation period.

This kind of reactor has been and is under development within several European Projects (e.g., HTR-N1 [21], PUMA [22], RAPHAEL [23]) to achieve attractive goals in a future energy scenario, curbing the $\mathrm{CO}_{2}$ emissions and reducing the energy cost.

In particular, as underlined by the Sustainable Nuclear Energy-Technical Platform (SNE-TP), HTR is in a privileged 
TABLE 4: EPR irradiation parameters: k-eff and burnup behaviour during irradiation.

\begin{tabular}{lccc}
\hline & k-eff behaviour during irradiation & Burn-up \\
\hline efpd & k-eff & pcm & GWd/tonHM \\
0 & 1.32984 & \pm 93 & 0.000 \\
60 & 1.26447 & \pm 92 & 1.995 \\
120 & 1.24461 & \pm 91 & 3.991 \\
180 & 1.22331 & \pm 90 & 5.986 \\
240 & 1.20226 & \pm 89 & 7.981 \\
300 & 1.18313 & \pm 87 & 9.976 \\
360 & 1.1624 & \pm 95 & 11.972 \\
420 & 1.1453 & \pm 89 & 13.967 \\
480 & 1.12973 & \pm 92 & 15.962 \\
540 & 1.11207 & \pm 94 & 17.957 \\
600 & 1.09508 & \pm 96 & 19.953 \\
630 & 1.12319 & \pm 93 & 19.953 \\
690 & 1.07986 & \pm 85 & 21.948 \\
750 & 1.0642 & \pm 90 & 23.943 \\
810 & 1.04939 & \pm 88 & 25.938 \\
870 & 1.03414 & \pm 88 & 27.934 \\
930 & 1.01997 & \pm 95 & 29.929 \\
990 & 1.0048 & \pm 94 & 31.924 \\
1050 & 0.99319 & \pm 91 & 33.920 \\
\hline
\end{tabular}

position to address nonelectricity energy needs because it could provide an early nuclear process heat production without waiting for the Gen-IV development [24].

As just indicated, HTR is a flexible system able to accommodate a wide variety of mixtures of fuels without any significant modification of the core design and it could reach very high burn-ups, which are far beyond the possibilities offered by other than fast reactors (except the particular case of molten salt reactors).

In the past, considerable experience on HTR technology has been accumulated, and two technology demonstrator reactors are in operation nowadays: the HTTR and the HTR10.

The HTTR is a prismatic core (150 fuel blocks) reactor in Japan of $30 \mathrm{MW}_{\text {th }}$ containing $\mathrm{UO}_{2}$ [25]. Instead the HTR-10 is a pebble bed core reactor of $10 \mathrm{MW}_{\text {th }}$ currently operating in China that first attained criticality in 2000 [26].

Finally, the reactor proposed in this work, is a pebble bed core reactor (PBMR like) with a core diameter of about $3700 \mathrm{~mm}$ (without considering the radial reflector). The fuel element adopted is a pebble containing CP (TRISO), as shown in Figure 6.

In order to model this reactor, some specific parameters have been used and a summary of them is presented in Table 5. Please note the core has been simulated in a "realistic" way, so the moderator/fuel ratio in the MCNP model for PBMR approximates to that of the real core.

In particular only $1 / 12$ of total core has been simulated as shown in Figure 7. In this figure only a simplified sketch is presented where it is possible to distinguish between the fuel zone (fuchsia zone) and the surrounded nonfuelled region
TABLE 5: PBMR parameters adopted for the model.

\begin{tabular}{|c|c|}
\hline \multicolumn{2}{|c|}{ Reactor design parameters } \\
\hline Thermal power & $433 \mathrm{MW}_{\text {th }}$ \\
\hline Pebble radius & $30 \mathrm{~mm}$ \\
\hline Packing fraction & 0.61 \\
\hline \multicolumn{2}{|c|}{ Core dimensions } \\
\hline Internal radius & $100 \mathrm{~cm}$ \\
\hline External radius & $185 \mathrm{~cm}$ \\
\hline Height & $1300 \mathrm{~cm}$ \\
\hline \multicolumn{2}{|c|}{ Reflector dimension } \\
\hline Rex central reflector & $100 \mathrm{~cm}$ \\
\hline Rin radial reflector & $185 \mathrm{~cm}$ \\
\hline Rex radial reflector & $275 \mathrm{~cm}$ \\
\hline Temperature & $1200 \mathrm{~K}$ \\
\hline Density & $1.74 \mathrm{~g} / \mathrm{cm}^{3}$ \\
\hline \multicolumn{2}{|c|}{ Pebble parameters } \\
\hline Kernel (Rex) & $0.01 \mathrm{~cm}$ \\
\hline Fuel density & $10.89 \mathrm{~g} / \mathrm{cm}^{3}$ \\
\hline Fuel temperature & $1200 \mathrm{~K}$ \\
\hline Buffer (Rex) & 0.019 \\
\hline Buffer density & $1.05 \mathrm{~g} / \mathrm{cm}^{3}$ \\
\hline Buffer temperature & $1200 \mathrm{~K}$ \\
\hline Inner PyC (Rex) & 0.023 \\
\hline PyC density & $1.90 \mathrm{~g} / \mathrm{cm}^{3}$ \\
\hline PyC temperature & $1200 \mathrm{~K}$ \\
\hline SiC layer (Rex) & 0.0265 \\
\hline SiC density & $3.18 \mathrm{~g} / \mathrm{cm}^{3}$ \\
\hline SiC temperature & $1200 \mathrm{~K}$ \\
\hline Outer PyC (Rex) & 0.0305 \\
\hline PyC density & $1.90 \mathrm{~g} / \mathrm{cm}^{3}$ \\
\hline PyC temperature & $1200 \mathrm{~K}$ \\
\hline
\end{tabular}

(blue part). Anyway in the complete model used in each pebble the heterogeneous matrix has been simulated, taking into account all the layers composing of the TRISO particles.

In the model adopted the composition of fuel chosen is calculated cording to the EPR discharged fuel and it is shown in Table 6. As shown in Table 6, the composition adopted in this preliminary calculation is analogous to the isotopic composition of $\mathrm{Pu}$ and $\mathrm{Np}$ obtained after the extraction from the EPR.

As anticipated this has to be considered a simplification. In any case, this assumption was made to reduce calculation time (in this first preliminary evaluation) and an additional improvement will be necessary for an accurate analysis, where the decay time and the relative composition changes will be correctly simulated.

The irradiation period was simulated by BGCore burnup code [20], considering a single irradiation cycle of 1500 EFPD. The fuel loading scheme is based on a continuous pebbles recirculation. So, the pebbles present for a fixed time in the core are at different levels of burn-up. Due to model limitations, in this preliminary configuration, where the core has been simulated as a steady core, the pebbles 


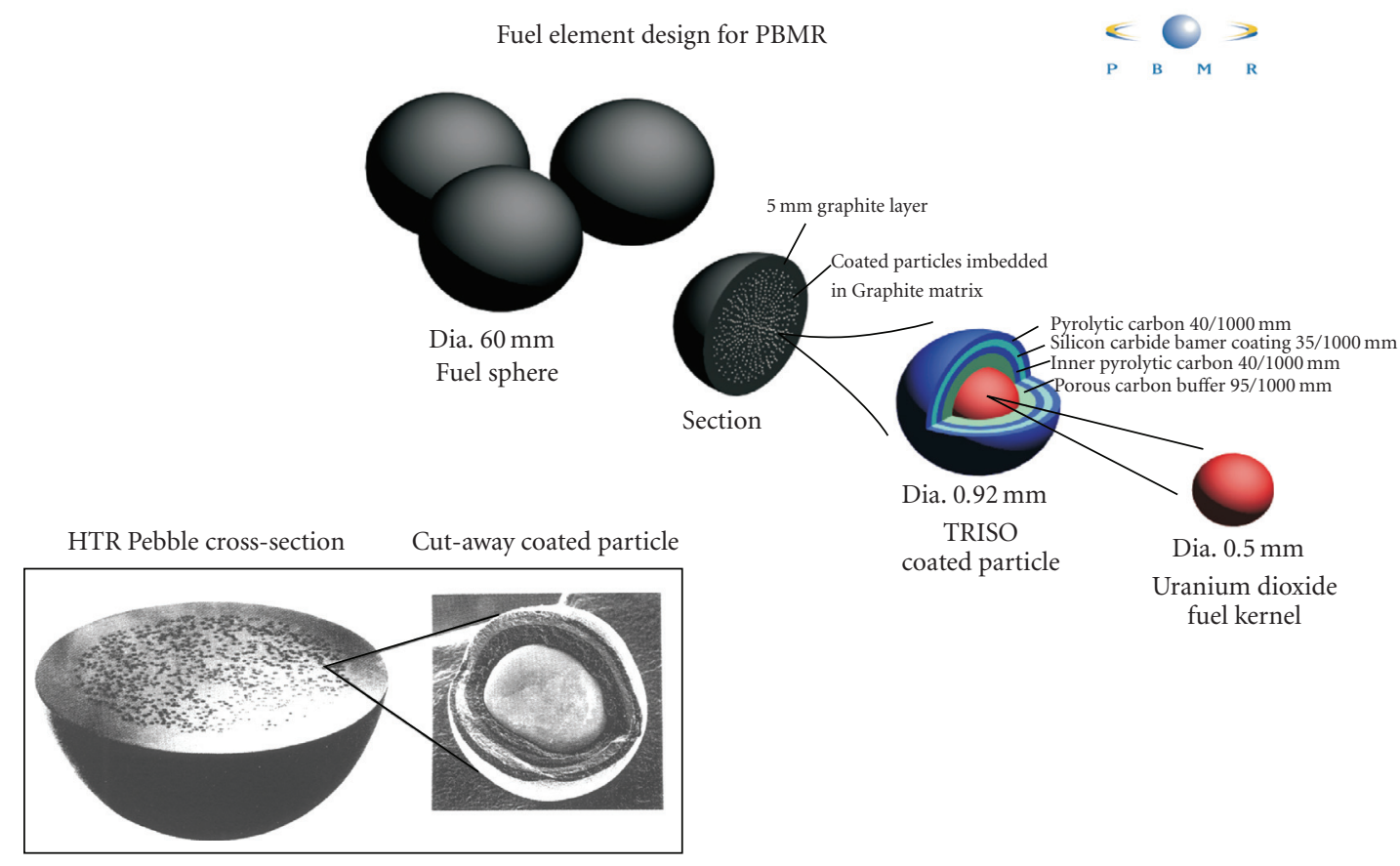

Figure 6: Fuel element design for HTR: pebble fuel containing TRISO CPs.

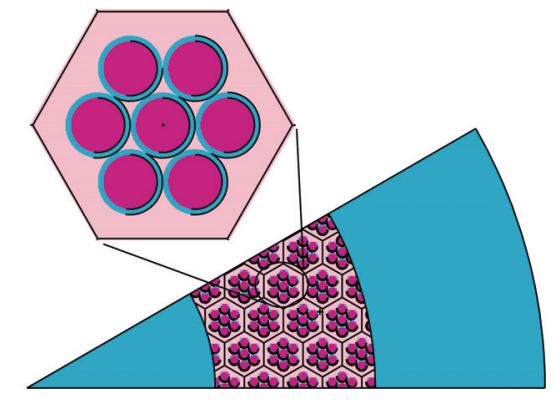

FIGURE 7: MCNP model of PBMR reactor.

were considered exhaust when the global k-eff becomes lower than unity. (Please note that the real PBMR will not be fuelled with pebbles at the same burn-up level, but with a mixture of pebbles at different burn-ups: the real discharge burn-up in principle could be extremely high, that is, up to twice the assumed discharge burnup. On the other hand, we have not took into account leakages and effects related to the structures surrounding the core, so this preliminary and conservative assumption could be acceptable.) In the calculations performed the residence time of the pebble inside the core has been estimated to be about 850 EFPD.

The global k-eff behavior during the irradiation is shown in Figure 8 and additional details (burn-up and standard error) are summarized in Table 7. As shown in the latter mentioned table, the burn-up reachable after 850 efpd, is $\sim 500 \mathrm{GWd} /$ tonHM, a conservative value that whatever enables to underline the good PBMR behavior with respect to the fuel exploitation.

TABLE 6: Isotopic composition of PBMR fuel (atomic fraction).

\begin{tabular}{lc}
\hline Isotope & Fuel Composition \\
\hline Np235 & $1.46 \mathrm{E}-10$ \\
Np236 & $6.42 \mathrm{E}-08$ \\
Np237 & $1.55 \mathrm{E}-02$ \\
Np238 & $3.76 \mathrm{E}-05$ \\
Np239 & $2.78 \mathrm{E}-03$ \\
Pu236 & $1.39 \mathrm{E}-10$ \\
Pu237 & $6.66 \mathrm{E}-09$ \\
Pu238 & $4.02 \mathrm{E}-03$ \\
Pu239 & $2.21 \mathrm{E}-01$ \\
Pu240 & $7.24 \mathrm{E}-02$ \\
Pu241 & $4.33 \mathrm{E}-02$ \\
Pu242 & $1.13 \mathrm{E}-02$ \\
Pu243 & $2.60 \mathrm{E}-06$ \\
Pu244 & $3.60 \mathrm{E}-07$ \\
O16 & $6.30 \mathrm{E}-01$ \\
\hline
\end{tabular}

Please note that the Xe effect has been "spread" (due to the chosen time steps) over the first 25 days (i.e., on the whole first time step).

5.3. GCFR Simulation. After the fuel irradiation in a HTR, the last step simulated is the burning in a Gas-Cooled Fast Reactor (GCFR) loaded with $\mathrm{Pu}$ and MAs coming from the previous reactor. Even in this case the fuel extracted from the previous reactor is inserted directly in the final facility adopted in the cycle. Of course, as future development, the correct evaluation of cooling time after PBMR and 
TABLE 7: HTR irradiation parameters: k-eff and burnup behaviour during irradiation.

\begin{tabular}{|c|c|c|c|}
\hline \multicolumn{3}{|c|}{ K-eff behaviour during irradiation } & \multirow{2}{*}{$\frac{\text { Burn-up }}{\text { GWd/tonHM }}$} \\
\hline efpd & k-eff & $\mathrm{pcm}$ & \\
\hline 0 & 1.28736 & \pm 130 & 0.000 \\
\hline 25 & 1.24676 & \pm 129 & 12.568 \\
\hline 50 & 1.2404 & \pm 125 & 25.136 \\
\hline 75 & 1.2316 & \pm 121 & 37.704 \\
\hline 100 & 1.22221 & \pm 121 & 50.272 \\
\hline 125 & 1.21924 & \pm 123 & 62.840 \\
\hline 150 & 1.213 & \pm 125 & 75.408 \\
\hline 175 & 1.20535 & \pm 129 & 87.976 \\
\hline 200 & 1.19871 & \pm 119 & 100.540 \\
\hline 225 & 1.19139 & \pm 131 & 113.110 \\
\hline 250 & 1.18784 & \pm 121 & 125.680 \\
\hline 275 & 1.18232 & \pm 123 & 138.250 \\
\hline 300 & 1.17541 & \pm 125 & 150.820 \\
\hline 325 & 1.16742 & \pm 119 & 163.380 \\
\hline 350 & 1.16256 & \pm 123 & 175.950 \\
\hline 375 & 1.15622 & \pm 126 & 188.520 \\
\hline 400 & 1.15019 & \pm 124 & 201.090 \\
\hline 425 & 1.14296 & \pm 118 & 213.660 \\
\hline 450 & 1.13729 & \pm 121 & 226.230 \\
\hline 475 & 1.13081 & \pm 123 & 238.790 \\
\hline 500 & 1.12329 & \pm 123 & 251.360 \\
\hline 525 & 1.11716 & \pm 111 & 263.930 \\
\hline 550 & 1.10962 & \pm 118 & 276.500 \\
\hline 575 & 1.09993 & \pm 123 & 289.070 \\
\hline 600 & 1.09524 & \pm 124 & 301.630 \\
\hline 625 & 1.08551 & \pm 107 & 314.200 \\
\hline 650 & 1.08023 & \pm 121 & 326.770 \\
\hline 675 & 1.07045 & \pm 122 & 339.340 \\
\hline 700 & 1.06385 & \pm 122 & 351.910 \\
\hline 725 & 1.05637 & \pm 116 & 364.470 \\
\hline 750 & 1.04411 & \pm 119 & 377.040 \\
\hline 775 & 1.03984 & \pm 114 & 389.610 \\
\hline 800 & 1.03049 & \pm 115 & 402.180 \\
\hline 825 & 1.01761 & \pm 108 & 414.750 \\
\hline 850 & 1.01017 & \pm 116 & 427.310 \\
\hline 875 & 0.99903 & \pm 116 & 439.880 \\
\hline
\end{tabular}

reprocessing and fabrication times (and feasibility) of GCFR fuel has to be analysed in order to have a more correct approach to the problem.

The choice to insert a GCFR as last facility for the symbiotic cycle is in agreement with sustainability and economic goals proposed in Generation IV [2]. In fact this facility, as it will be further clarified in the results discussion

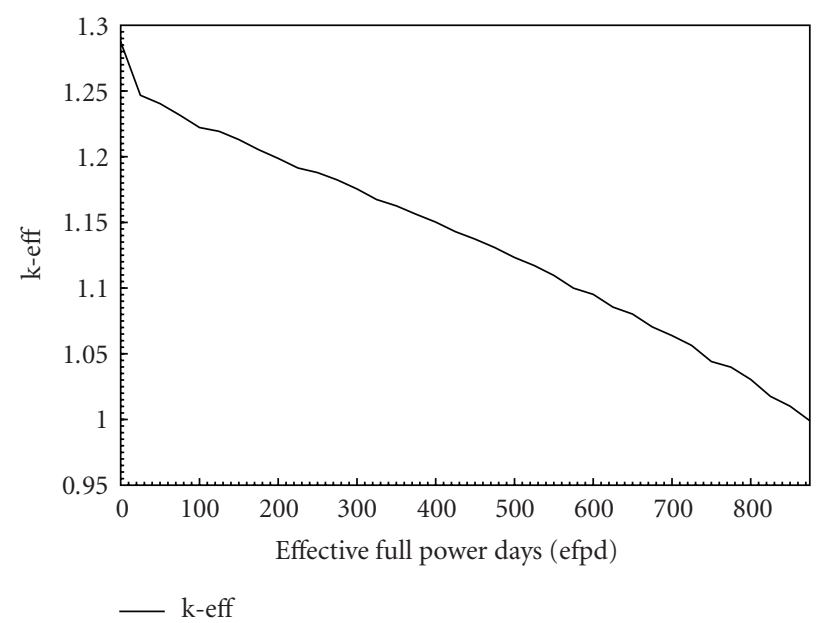

FIGURE 8: HTR simplified model: k-eff behaviour during irradiation period.

section, enables to reduce considerably the confinement time necessary for the final disposal.

This reactor has specific characteristic for what concerns the fuel optimised use (high attainable burn-up and long reactivity limited irradiation time before becoming subcritical). In addition by using directly the high temperature reached by the Helium coolant (adopting the Brayton thermodynamic cycle), it could reach a high efficiency.

This kind of reactor is one of the six concepts proposed for development by the Generation IV international forum, and it could be considered interesting, as the HTR one, for the use in Hydrogen production and for other industrial processes.

Major design parameters of GCFR are summarized in Table 8 , as presented by [2].

The model adopted in this work is a GCFR " $\mathrm{E}$ " $\left(2400 \mathrm{MW}_{\text {th }}\right)$ He-cooled fast reactor [27]. It is loaded by hexagonal fuel assemblies containing plates made of a (U,Pu)C and SiC matrix (Figure 9). The choice of carbide allows to improve the fuel performance.

One of the major advantages of this facility is the low content of parasitic absorbers, that enables GCFR to reach criticality with a fuel composed of $82 \%$ (as an atomic fraction) Depleted Uranium (DU) as well as to sustain very long irradiation period without becoming subcritical. Of course, the irradiation period has to be optimized taking into account the integrity of fuel structures, where the major cause of limitation probably will derive from the radiation damage (expressed in displacements from atoms, dpa) causes by fast neutrons and gamma spectra.

In the model adopted the composition of fuel chosen is based on the PBMR discharged fuel and it is shown in Table 9.

The irradiation period was simulated by BGCore burnup code [20], considering an irradiation cycles of 5500 EFPD before the reactor becomes subcritical $(\mathrm{k}$-eff $<1)$.

The global k-eff behavior during the irradiation is shown in Figure 10 and additional details (burn-up and std. error) are summarized in Table 10. 
TABLE 8: GCFR Major target parameter: reference values.

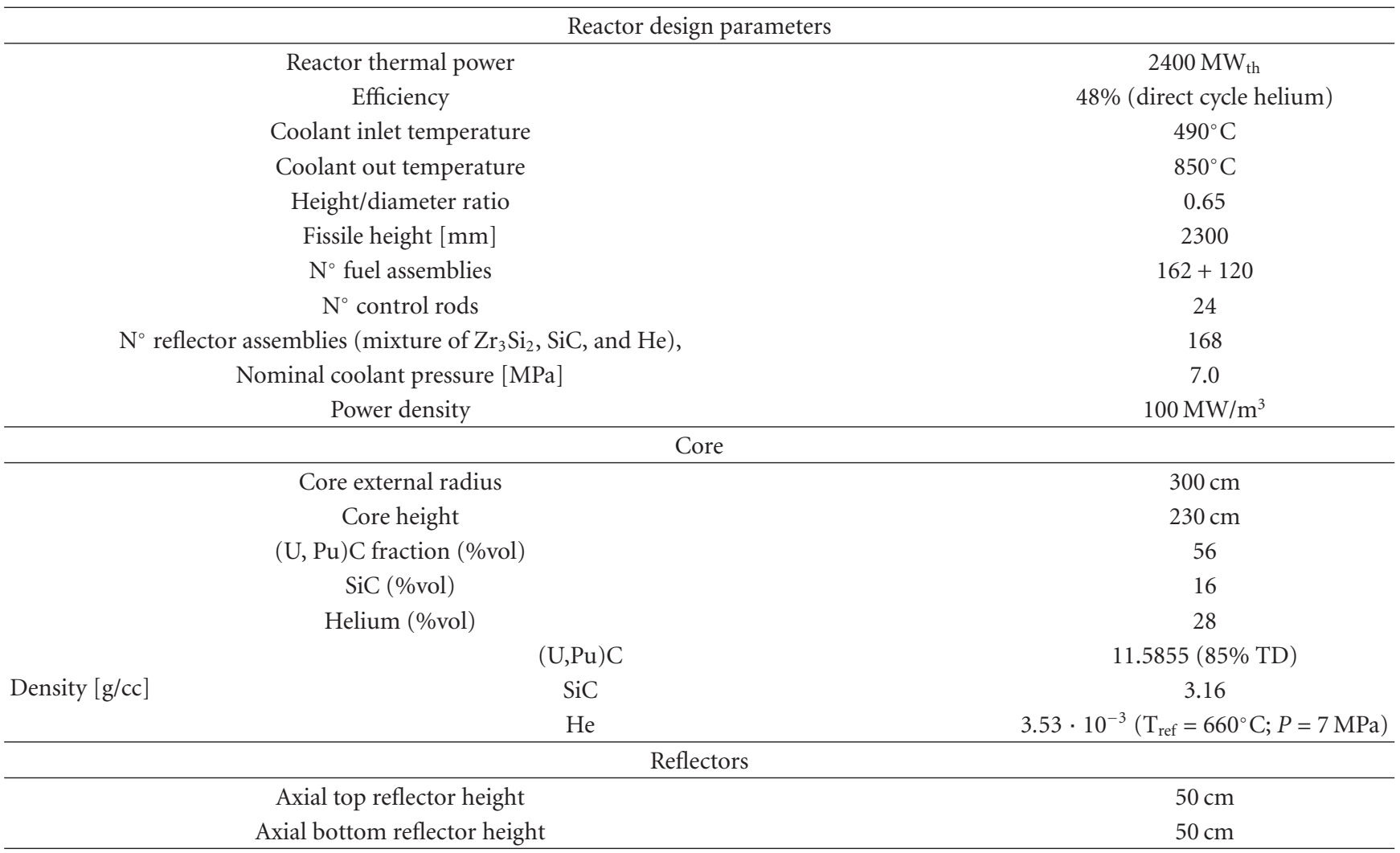

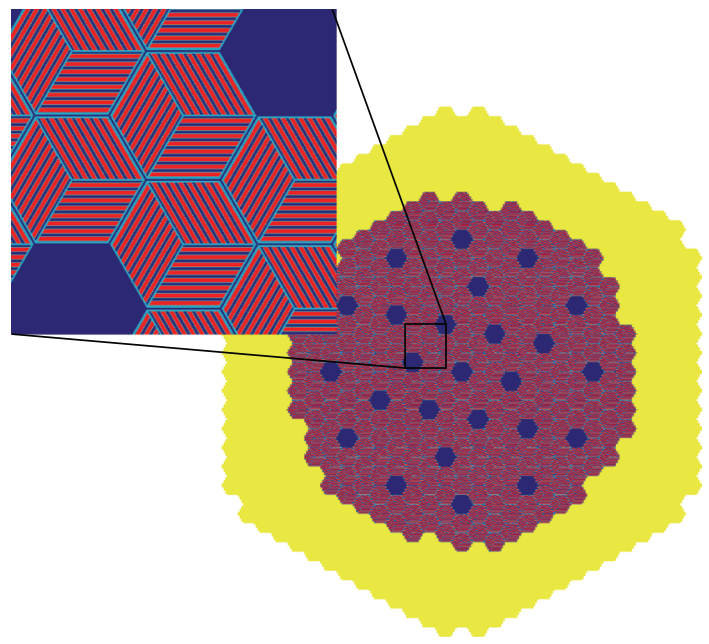

FIGURE 9: MCNP model of GCFR reactor.

\section{Discussion of the Obtained Results}

The analysis of the symbiotic cycle proposed is inserted in a wider context: the investigation of possible strategies for the nuclear fuel cycle closure.

For this reason the comparison between the symbiotic cycle and a reference scenario has been performed to underline the advantages and the drawbacks of this strategy.
TABLE 9: Isotopic composition of GCFR fuel (atomic fraction).

\begin{tabular}{lc}
\hline Isotope & Fuel composition \\
\hline U235 & $1.79 \mathrm{E}-03$ \\
U238 & $7.21 \mathrm{E}-01$ \\
$\mathrm{~Np} 237$ & $8.52 \mathrm{E}-03$ \\
$\mathrm{~Np} 238$ & $1.48 \mathrm{E}-05$ \\
Pu238 & $5.36 \mathrm{E}-03$ \\
$\mathrm{Pu} 239$ & $4.76 \mathrm{E}-02$ \\
$\mathrm{Pu} 240$ & $4.85 \mathrm{E}-02$ \\
$\mathrm{Pu} 241$ & $3.12 \mathrm{E}-02$ \\
$\mathrm{Pu} 242$ & $1.88 \mathrm{E}-02$ \\
$\mathrm{Pu} 243$ & $2.30 \mathrm{E}-06$ \\
$\mathrm{Pu} 244$ & $8.46 \mathrm{E}-07$ \\
$\mathrm{C}$ & $6.61 \mathrm{E}-02$ \\
$\mathrm{Si} 28$ & $4.65 \mathrm{E}-02$ \\
Si29 & $2.44 \mathrm{E}-03$ \\
Si30 & $1.68 \mathrm{E}-03$ \\
He & $1.41 \mathrm{E}-04$ \\
\hline
\end{tabular}

The reference scenario chosen is the direct disposal of SNF coming from EPR, without reprocessing $\mathrm{Pu}$ (the socalled once-through strategy), that is the strategy at the moment worldwide (with some exceptions) adopted for the LWRs but that has to be changed if the long-term 


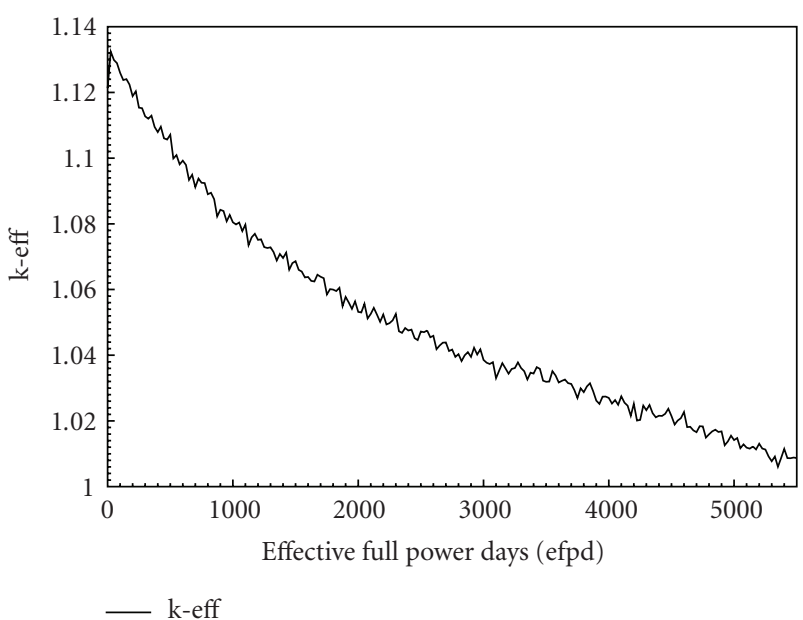

FIGURE 10: GCFR simplified model: k-eff behaviour during irradiation period.

TABLE 10: GCFR irradiation parameters: k-eff and burnup behaviours during irradiation.

\begin{tabular}{lccc}
\hline \multicolumn{2}{c}{$\begin{array}{c}\text { k-eff behaviour during irradiation } \\
\text { efpd }\end{array}$} & k-eff & $\begin{array}{c}\text { Burn-up } \\
\text { GWd/tonHM }\end{array}$ \\
\hline 0 & 1.1213 & \pm 129 & 0.000 \\
50 & 1.12987 & \pm 130 & 1.578 \\
100 & 1.12598 & \pm 123 & 3.156 \\
200 & 1.11886 & \pm 121 & 6.312 \\
300 & 1.11271 & \pm 130 & 9.469 \\
400 & 1.10792 & \pm 128 & 12.625 \\
500 & 1.10713 & \pm 130 & 15.781 \\
600 & 1.09925 & \pm 137 & 18.937 \\
700 & 1.09116 & \pm 128 & 22.093 \\
800 & 1.08902 & \pm 112 & 25.250 \\
900 & 1.08428 & \pm 109 & 28.406 \\
1000 & 1.08047 & \pm 111 & 31.562 \\
1500 & 1.06864 & \pm 115 & 47.343 \\
2000 & 1.05319 & \pm 126 & 63.124 \\
2500 & 1.04722 & \pm 110 & 78.905 \\
3000 & 1.03857 & \pm 119 & 94.686 \\
3500 & 1.03191 & \pm 114 & 111.632 \\
4000 & 1.02702 & \pm 106 & 129.205 \\
4500 & 1.02147 & \pm 105 & 147.288 \\
5000 & 1.01417 & \pm 101 & 165.428 \\
5500 & 1.0087 & \pm 105 & 183.801 \\
\hline
\end{tabular}

sustainability for the nuclear electricity production has to be considered.

The analysis of various strategies to close the nuclear fuel cycle matches with one of the major questions that scientific community has to answer: how minimize the final wastes (and their potential risk) to be sent to geological disposal. Question still opened, a critical issue from the public opinion acceptability point of view.
A deep analysis of the minimization of volumes involved is important (even if the quantity produced up to now could be considered negligible with respect to the other conventional wastes related to the energy chain, e.g., coal energy chain). However, the evaluation of time needed to reach the Uranium reference level is an even more important parameter to be considered. This parameter could be evaluated by means of the radiotoxicity versus time evolution behaviour.

Finally the SNF decay heat evolutions (an important parameter for the integrity and the design of the geological disposal) have been evaluated.

Other parameters are not considered in this work but they will be very important for the choice of the reference cycle to adopt. For instance, a deeper analysis of the uranium-plutonium resources optimization is significant for the long-term sustainability.

The first step for a correct comparison between the two proposed scenarios is the characterization of the oncethrough by means of the already underlined parameters (radiotoxicity and power decay).

In order to perform this analysis, after the normalization to 1 ton of discharged HM, the evolution of spent fuel composition coming from EPR has been simulated by means of CARL2.3 depletion code [18]. It does not use fluxes and/or cross-sections for its calculations; it is simply a depletion code implementing a set of Bateman equations. CARL2.3's input is the output masses given by the neutron calculations. This code, developed at the University of Pisa, enables to solve the Bateman equations, starting from 55 father isotopes (mainly $\mathrm{U}, \mathrm{Pu}$, and $\mathrm{MAs}$ but also the long live fission products). These 55 fathers are the most significant isotopes for the radiotoxicity point of view (the CARL 2.3 code requires in input the masses (expressed in grams) of the following 55 elements: $\mathrm{Th}^{232}, \mathrm{U}^{232}, \mathrm{U}^{233}, \mathrm{U}^{234}, \mathrm{U}^{235}, \mathrm{U}^{238}$, $\mathrm{Np}^{237}, \mathrm{Pu}^{238}, \mathrm{Pu}^{239}, \mathrm{Pu}^{240}, \mathrm{Pu}^{241}, \mathrm{Pu}^{242}, \mathrm{Pu}^{243}, \mathrm{Pu}^{244}, \mathrm{Am}^{241}$, $\mathrm{Am}^{242 m}, \mathrm{Am}^{243}, \mathrm{Cm}^{242}, \mathrm{Cm}^{243}, \mathrm{Cm}^{244}, \mathrm{Cm}^{245}, \mathrm{Rb}^{87}, \mathrm{Sr}^{90}$, $\mathrm{Zr}^{93}, \mathrm{Nb}^{94}, \mathrm{Tc}^{99}, \mathrm{Pd}^{107}, \mathrm{Sn}^{126}, \mathrm{I}^{129}, \mathrm{Cs}^{135}, \mathrm{Cs}^{137}, \mathrm{Sm}^{147}, \mathrm{Sm}^{151}$, $\mathrm{Eu}^{154}, \mathrm{Se}^{7}, \mathrm{Cr}^{51}, \mathrm{Mn}^{56}, \mathrm{Fe}^{59}, \mathrm{Co}^{60}, \mathrm{Ni}^{65}, \mathrm{Cu}^{64}, \mathrm{Zn}^{65}, \mathrm{Zn}^{69}$, $\mathrm{Zr}^{95}, \mathrm{Mo}^{99}, \mathrm{Ta}^{182}, \mathrm{~W}^{187}, \mathrm{Na}^{24}, \mathrm{Ca}^{45}, \mathrm{Br}^{82}, \mathrm{Ba}^{140}, \mathrm{Ir}^{192}, \mathrm{Po}^{218}$, $\left.\mathrm{Ra}^{226}, \mathrm{Ra}^{228}\right)$; In fact as well known, the total radiotoxicity, as well as heat decay, is quantities driven by a few radionuclides. The radiotoxicity coefficients adopted are referred to ICRP72 values.

For the EPR once-through strategy, all the SNF is directed to geological disposal (MAs plus $\mathrm{Pu}$ ). The total radiotoxicity versus Time evolution of SNF coming from EPR is shown in Figure 11. The time to reach the fixed radiotoxicity Reference level (i.e., the so-called LOMBT [18]) is equal to $\sim 170000$ years. In this case all the discharged materials are considered as a waste.

If the contribution to the total radiotoxicity of each isotopes is taken into account (as shown in Figure 12), it is possible to underline that the major contribution for the long period depends on the Pu content evolution (black line in the Figure 12).

This consideration and the necessity to have a more optimised use of resources (that means to consider $\mathrm{Pu}$ as an optimal fuel for the development of nuclear reactors, 


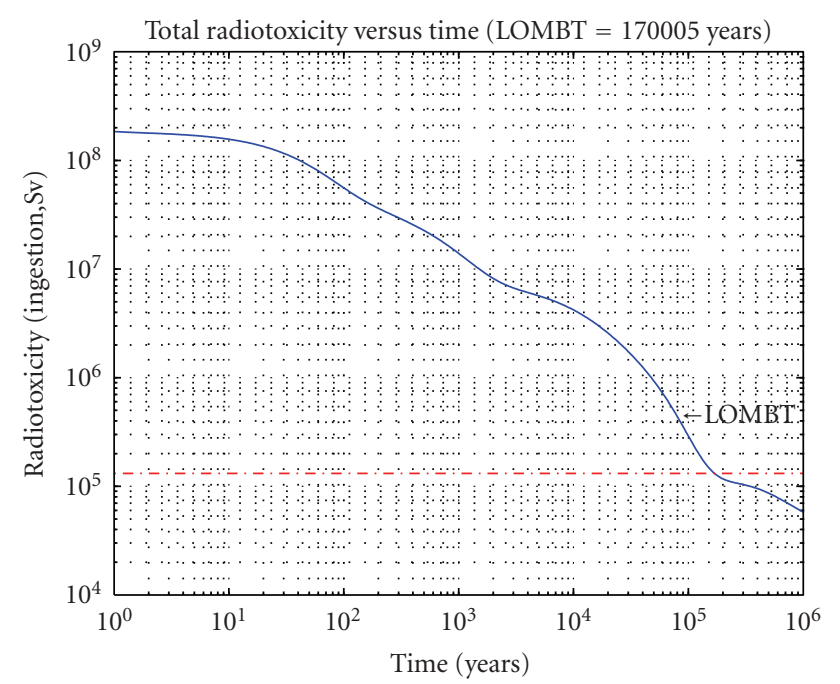

FIGURE 11: EPR Total radiotoxicity versus Time (values normalized to 1 ton $\mathrm{HM}$ ) (the number of evaluated points in the considered period (1-1E+06 years) is equal to 500$)$.

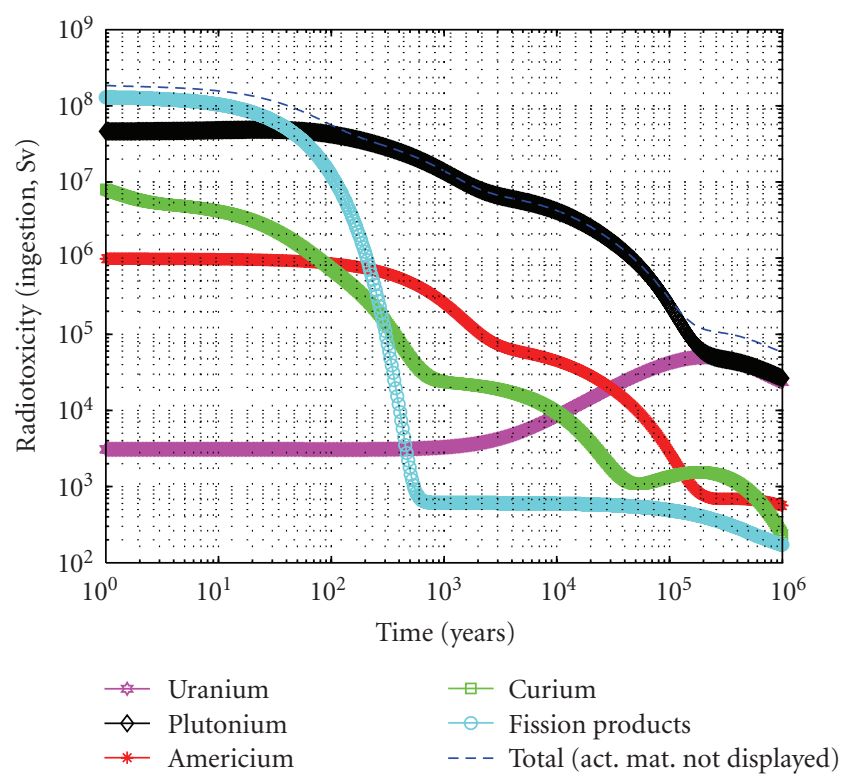

FIGURE 12: EPR contribution of each element to the total radiotoxicity versus time.

particularly fast spectrum ones) are at the basis of the analysis of different fuel strategies able to improve the use of the fuel.

Furthermore, as shown in Figure 13, Pu gives also the major contribution to the total Power Decay, that is the heat load source term for the long-term geological disposal (although for the first 300 years the major contributions to radiotoxicity and decay heat had arisen from fission products).

After the characterization of the reference scenario, some additional considerations have to be added to before comparing it with the simulated symbiotic cycle.

In the hypothesized scenario the SNF reprocessing has been assumed as important step but it has not modelled in

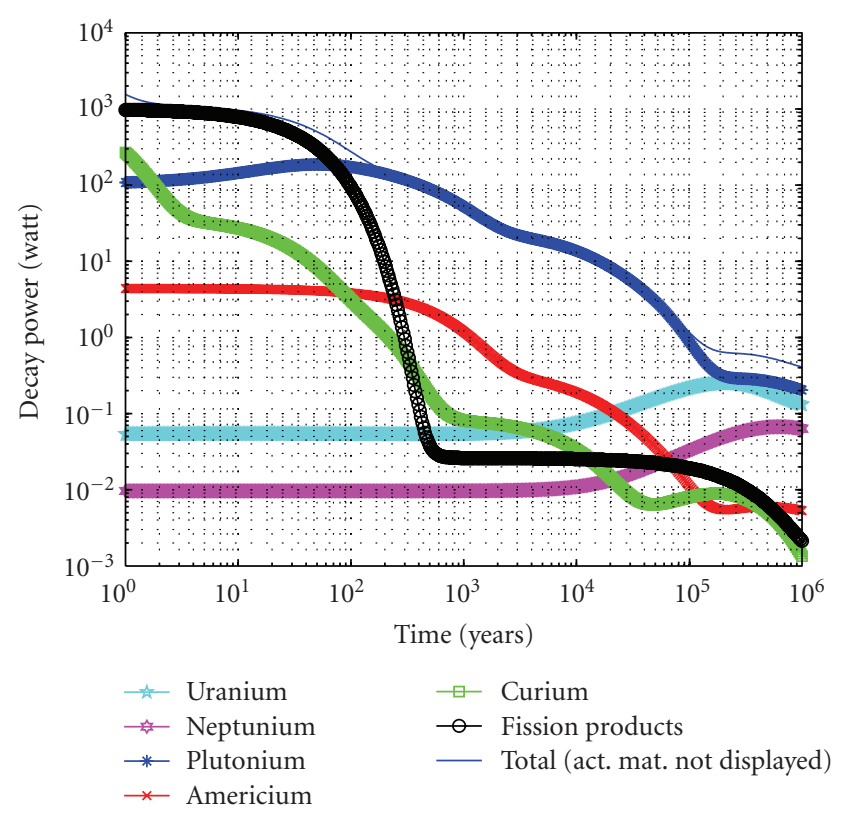

FIgURE 13: EPR contribution of each element to the total decay power versus time.

details. In particular the separation efficiency of the PUREX process $(0.1 \% \mathrm{Pu}$ left in wastes) is assumed as a reference value. We have assumed the feasibility of the separation of $\mathrm{Pu}+\mathrm{Np}$ from the other TRUs with an efficiency similar to PUREX process ( $0.1 \%$ left in waste). The real technological implementation of this process has to be further analyzed as a future development of the present research. As a result of the previous hypotheses, the symbiotic cycle simulated assumes HTR and GCFR initial fuels composed by $\mathrm{Pu}+\mathrm{Np}$ recycled from the previous reactor in the chain (resp., EPR and PBMR) plus additional materials (DU, SiC, etc.). One of the aim of these assumptions is to improve the $\mathrm{Pu}$ exploitation and, at least partially, to burn MA. It should be noted that the choice to exclude Am and Cm from the fresh "recycled" fuel is due to at least two different reasons [28].

(1) A fuel (re-)fabrication facility that have to manage $\mathrm{Cm}$ would have serious difficult, due to radiological and material issues.

(2) An efficient process to separate Am from Cm is far-off to be implemented (at least on an industrial scale).

As a first qualitative comparison among the $\mathrm{Pu}$ and MAs inventories after the irradiations in the three simulated reactors, Table 11 shows the inventory of the SNF (normalized to 1 ton of discharged HM, including $\mathrm{U}$, too) at the end of the irradiation periods.

Before going on with the analyses, it is useful to underline two points (more deeply analyzed in [27]):

(i) $1 \mathrm{PBMR}$ is able to burn the $\mathrm{Pu}+\mathrm{Np}$ inventory coming from $0.62 \mathrm{LWR}$;

(ii) 56 PBMR cores are capable for supplying the fuel mass to start 1 new GCFR core. 
TABLE 11: Inventory (values relative to 1 ton of $\mathrm{HM}$ ) of $\mathrm{Pu}$ and MAs after the irradiation in EPR, PBMR, and GCFR.

\begin{tabular}{lccc}
\hline Isotopes & $\mathrm{EPR}^{(1)}$ & $\begin{array}{c}\mathrm{PBMR}^{(2)} \\
\mathrm{g} / \text { ton }\end{array}$ & $\mathrm{GCFR}^{(3)}$ \\
\hline $\mathrm{Np} 237$ & $4.28 \mathrm{E}+02$ & $4.63 \mathrm{E}+04$ & $3.21 \mathrm{E}+03$ \\
$\mathrm{Pu} 238$ & $1.11 \mathrm{E}+02$ & $2.91 \mathrm{E}+04$ & $7.92 \mathrm{E}+03$ \\
$\mathrm{Pu} 239$ & $6.14 \mathrm{E}+03$ & $2.59 \mathrm{E}+05$ & $9.85 \mathrm{E}+04$ \\
$\mathrm{Pu} 240$ & $2.02 \mathrm{E}+03$ & $2.64 \mathrm{E}+05$ & $6.34 \mathrm{E}+04$ \\
$\mathrm{Pu} 241$ & $1.21 \mathrm{E}+03$ & $1.70 \mathrm{E}+05$ & $1.00 \mathrm{E}+04$ \\
$\mathrm{Pu} 242$ & $3.18 \mathrm{E}+02$ & $1.02 \mathrm{E}+05$ & $1.99 \mathrm{E}+04$ \\
$\mathrm{Pu} 243$ & $7.35 \mathrm{E}-02$ & $1.25 \mathrm{E}+01$ & $4.38 \mathrm{E}-01$ \\
$\mathrm{Pu} 244$ & $1.02 \mathrm{E}-02$ & $4.61 \mathrm{E}+00$ & $4.68 \mathrm{E}-02$ \\
$\mathrm{Am} 241$ & $3.53 \mathrm{E}+01$ & $1.20 \mathrm{E}+04$ & $5.58 \mathrm{E}+03$ \\
$\mathrm{Am} 242 \mathrm{~m}$ & $1.11 \mathrm{E}+00$ & $3.06 \mathrm{E}+02$ & $5.50 \mathrm{E}+02$ \\
$\mathrm{Am} 243$ & $5.08 \mathrm{E}+01$ & $1.78 \mathrm{E}+04$ & $4.78 \mathrm{E}+03$ \\
$\mathrm{Cm} 242$ & $9.15 \mathrm{E}+00$ & $2.53 \mathrm{E}+03$ & $2.26 \mathrm{E}+02$ \\
$\mathrm{Cm} 243$ & $1.58 \mathrm{E}-01$ & $3.94 \mathrm{E}+01$ & $2.86 \mathrm{E}+01$ \\
$\mathrm{Cm} 244$ & $1.17 \mathrm{E}+01$ & $4.39 \mathrm{E}+03$ & $2.38 \mathrm{E}+03$ \\
$\mathrm{Cm} 245$ & $5.62 \mathrm{E}-01$ & $1.66 \mathrm{E}+02$ & $3.86 \mathrm{E}+02$ \\
\hline
\end{tabular}

(1) 990 efpd- $\mathrm{UO}_{2}$ fuel $\left(4.3 \% \mathrm{U}^{235}\right.$ enrichment). ${ }^{(2)} 850 \mathrm{efpd}-\mathrm{Pu}-\mathrm{Np}$ content fuel. ${ }^{\left({ }^{3}\right)} 5500$ efpd-DU-Pu-Np content fuel (in inert matrix).

So the choice of comparing 1 ton of discharged HM for all the reactors has to be considered just as a first approximation, useful to have a qualitative idea but to be corrected if implemented in a more complex and complete scenario analysis.

In order to underline the advantages that the symbiotic cycle could bring about, after the irradiation in an EPR, the separation of $\mathrm{Pu}$ and $\mathrm{Np}$ is performed ( $0.1 \%$ left in waste). Under these conditions, the new radiotoxicity and the decay power versus time trends are shown in Figures 14, 15, and 16.

The analysis of total radiotoxicity versus time (Figure 14) shows a new LOMBT equal to $\sim 2150$ years (assuming only $\mathrm{Np}$ and Pu separation).

At the same time, if the contribution of each isotope is analysed (Figure 15) the major contribution to total radiotoxicity (for the long period) arisen from Americium and Curium chains (red and green lines, Figure 15). As shown in Figure 16, these elements are the major contribution to the power decay, too.

As anticipated, PBMR is the second reactor considered in the chosen cycle. This reactor is characterized by the possibility to accommodate a wide variety of mixtures of fuels without any significant modification of the core design and it could reach very high burn-ups.

For this reactor, it is not clear, at least at the moment, if the reprocessing of pebble will be performed or not. This is the reason why the case of direct disposal of pebble is shown in Figure 17 and considered as term of comparison for the case with $\mathrm{Pu}$ and $\mathrm{Np}$ separation adopted (99.9\% separation efficiency), shown in Figure 18. The LOMBT passes from $\sim 70100$ (direct disposal) to $\sim 3050$ years.

As already discussed, the $\mathrm{Pu}$ and $\mathrm{Np}$ reprocessing has been assumed as an important step to perform in order to reach a really sustainable cycle. For this reason a deeper

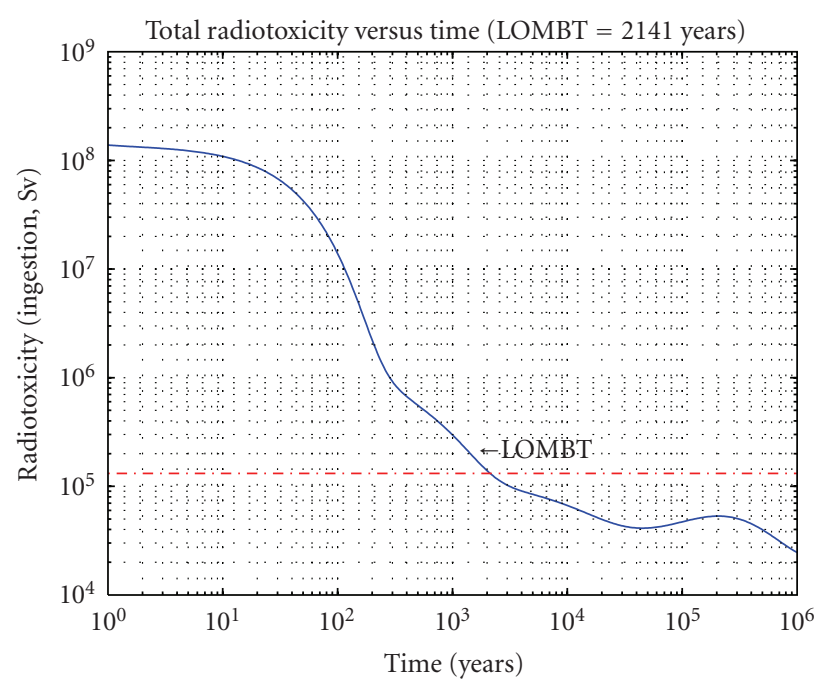

FIGURE 14: EPR total radiotoxicity versus time considering $0.1 \%$ of $\mathrm{Pu}$ and $\mathrm{Np}$ left in wastes (values normalized to 1 ton $\mathrm{HM})(0.1 \%$ of $\mathrm{Pu}+\mathrm{Np}$ left in waste (data assumed starting from what obtained for $\mathrm{Pu}$ in the PUREX process)).

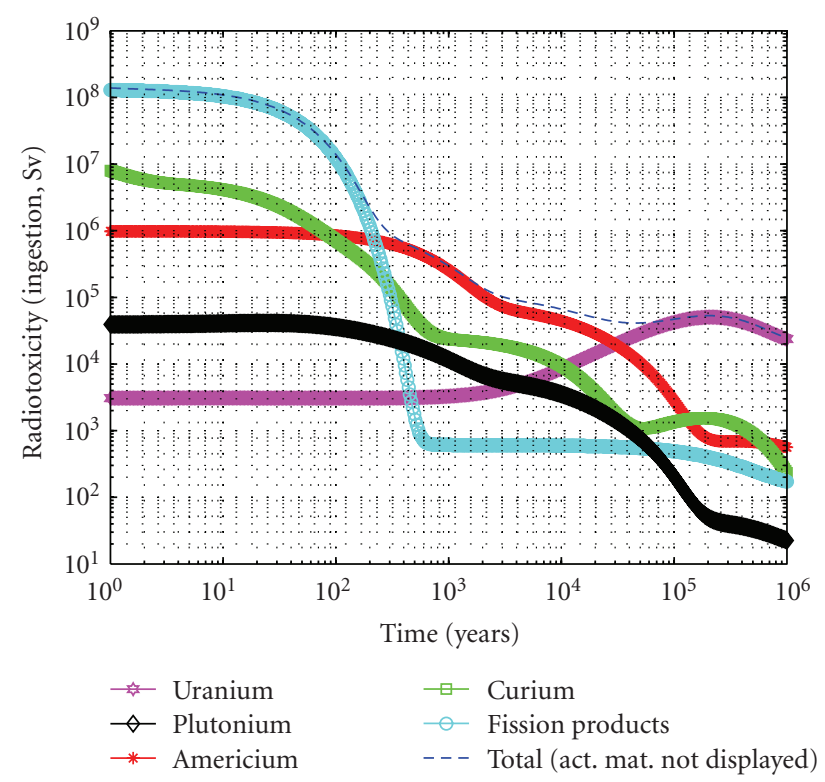

FIGURE 15: EPR contribution of each element to the total radiotoxicity versus time considering $99.9 \% \mathrm{Pu}$ and $\mathrm{Np}$ separation.

analysis for both the contributions to radiotoxicity and the decay power trends under this assumption has been performed. The obtained results are shown, respectively, in Figures 19 and 20.

As previously described, the last simulated facility is a GCFR. This kind of reactor is analysed in Gen-IV and it will became very attractive if the optimisation of resource involved will be taken into account.

The same approach adopted for the EPR and the HTR is applied to the GCFR evaluation. In fact the SNF radiotoxicity evolution without $\mathrm{Pu}$ and $\mathrm{Np}$ (only the $0.1 \%$ is left in waste) 


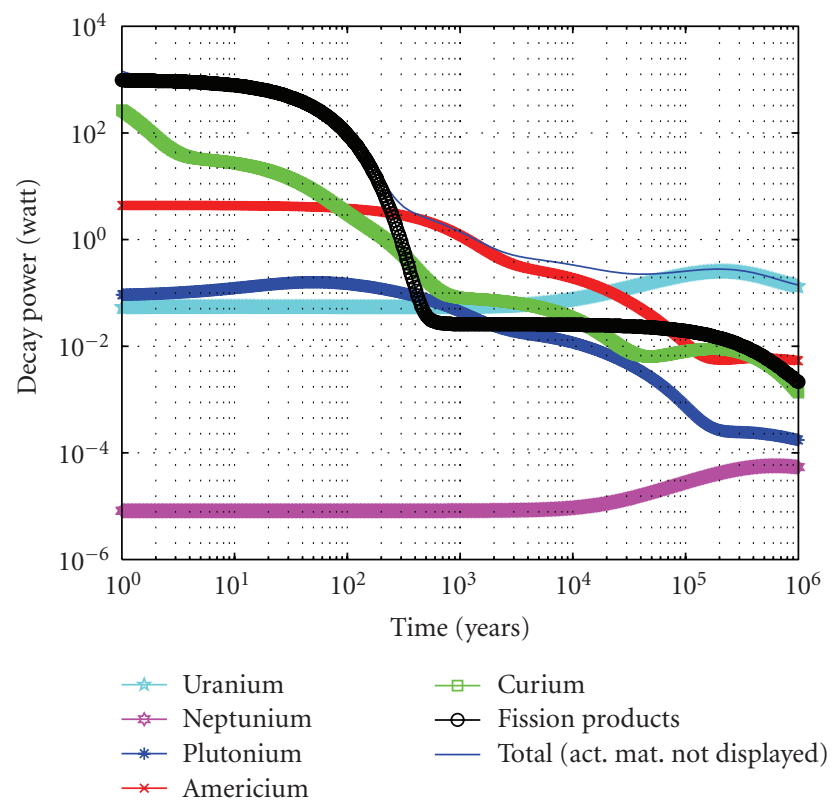

Figure 16: EPR contribution of each element to the total Decay Power versus time in the case of $99.9 \%$ of $\mathrm{Pu}$ and $\mathrm{Np}$ separation.

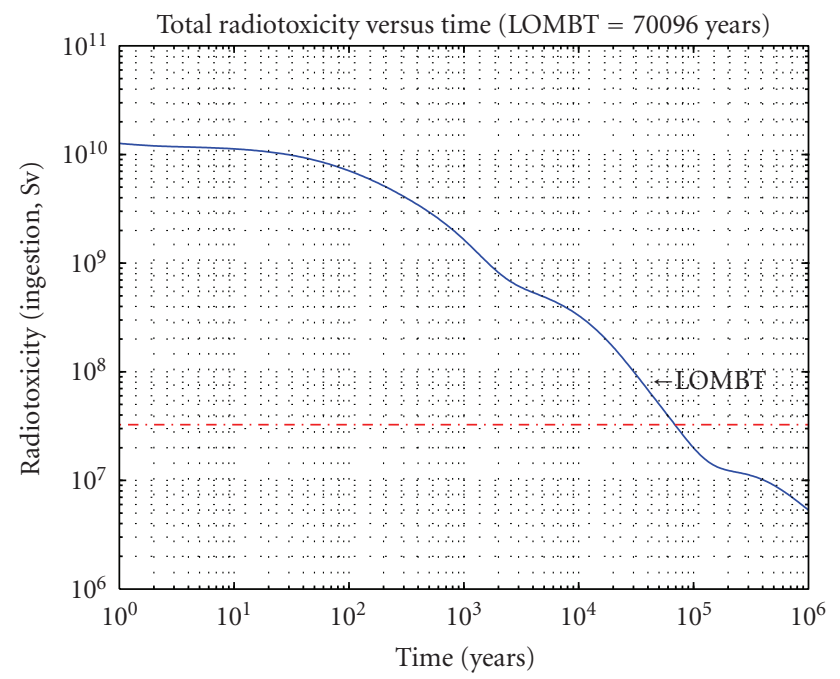

FIGURE 17: HTR (PBMR) total radiotoxicity versus time without pebble reprocessing.

has been simulated by means of CARL code, and shown in Figure 21 . The LOMBT is equal to $\sim 1550$ years, that is, a time comparable with typical human "historical" time and so it could be acceptable for the geological disposal.

If a radiotoxicity contribution analysis is performed (Figure 22), again $\mathrm{Cm}$ and $\mathrm{Am}$ are the major contributors (at least for the medium and the long-term). These elements are also the major causes for the heat decay load (Figure 23).

Finally it is important to have a look at the energy produced by each of the reactors (it has been assumed to have an utilization factor (for all the considered reactors) equal to $90 \%$ ). As already anticipated $1 \mathrm{PBMR}$ is able to burn the $\mathrm{Pu}+\mathrm{Np}$ inventory coming from $0.62 \mathrm{LWR}$ and $56 \mathrm{PBMR}$ cores are capable for supplying the fuel mass to start 1 new

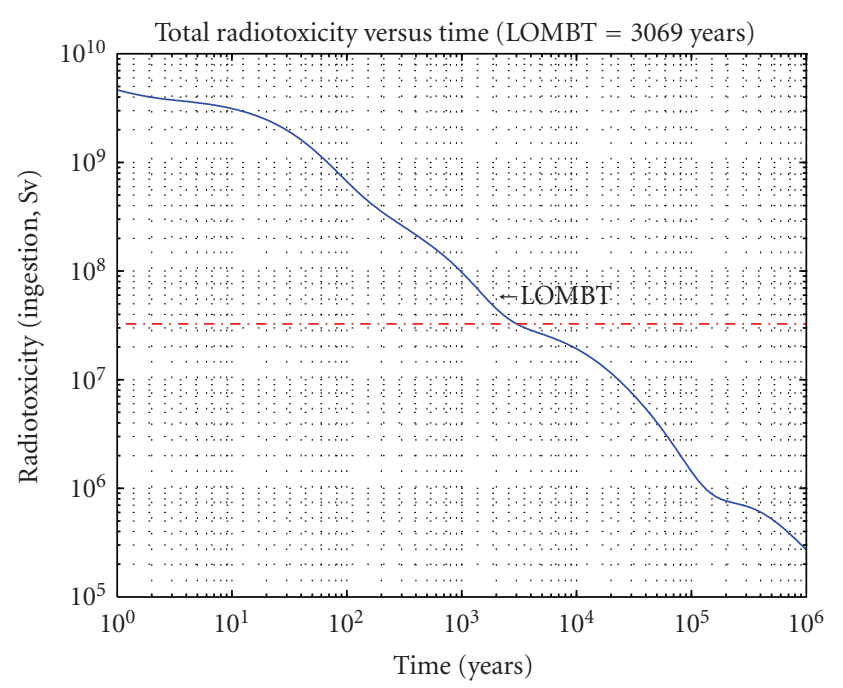

FIGURE 18: HTR (PBMR) total radiotoxicity versus time with pebble reprocessing $(0.1 \% \mathrm{Pu}$ and $\mathrm{Np}$ left in the final waste).

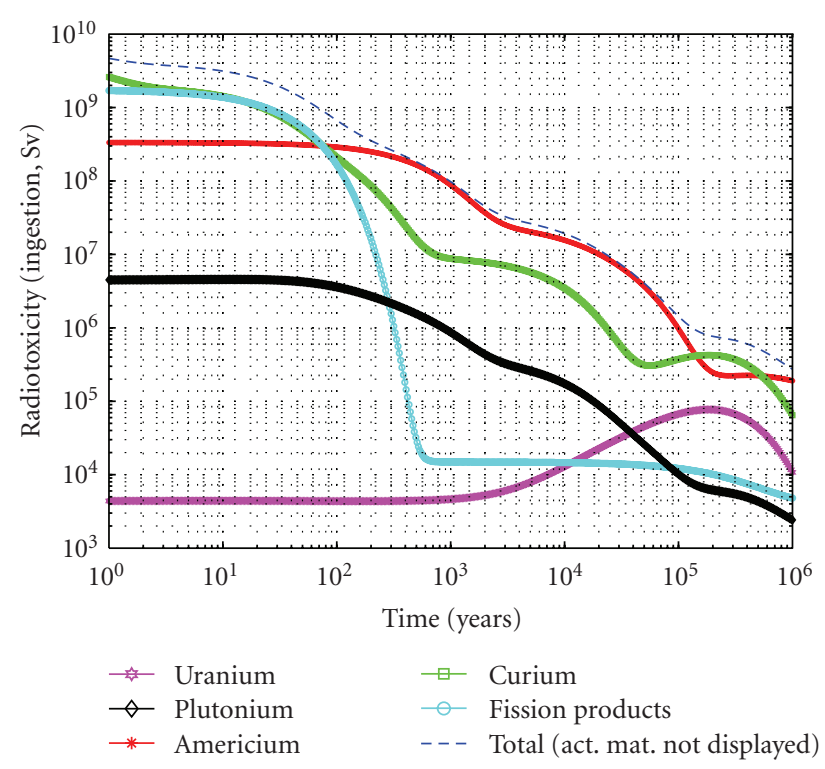

FIGURE 19: HTR (PBMR) contribution of each element to the total radiotoxicity versus time considering the $\mathrm{Pu}$ and $\mathrm{Np}$ separation.

GCFR core. So, in order to perform a "realistic" analysis, it was assumed (as a first approximation) to have in the chain [27]:
(i) 1 GCFR,
(ii) 56 PBMR,
(iii) $42 \mathrm{EPR}$.

The results are shown in Table 12 .

As a first consideration, it is important to highlight that, if we use an integrated EPR-PBMR-GCFR fuel cycle (instead of a single EPR), we can obtain a total electric energy equal to $630.54 \mathrm{TWh} /$ year (instead of only 529.62 $\mathrm{TWh}$ /year). Of course, this result can be obtained without consuming additional raw materials. 


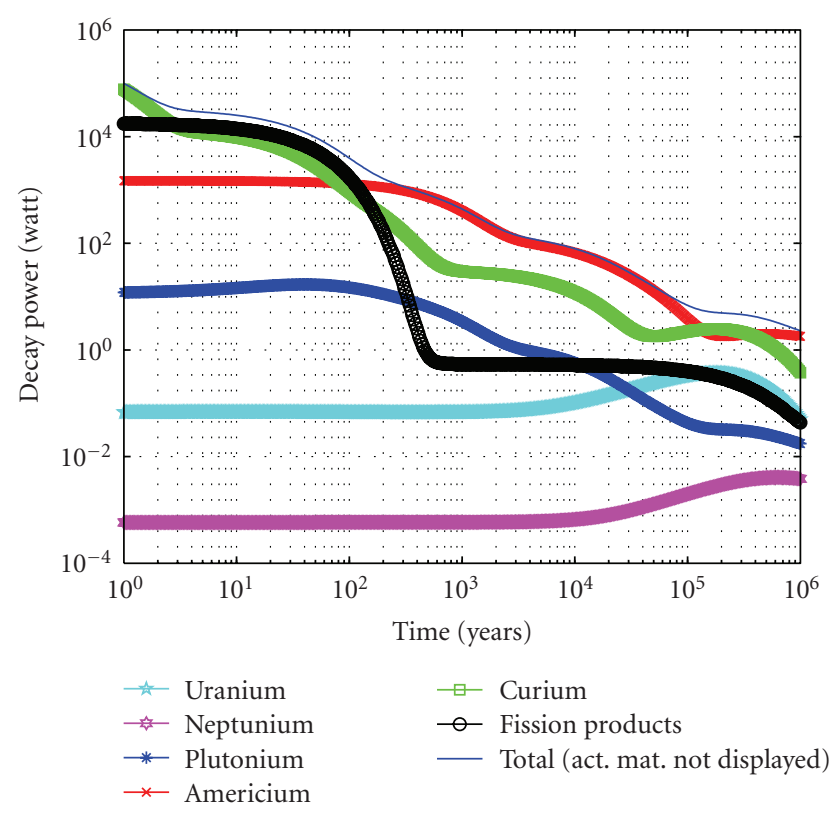

Figure 20: HTR (PBMR) contribution of each element to the total Decay Power versus time considering the $\mathrm{Pu}$ and $\mathrm{Np}$ separation.

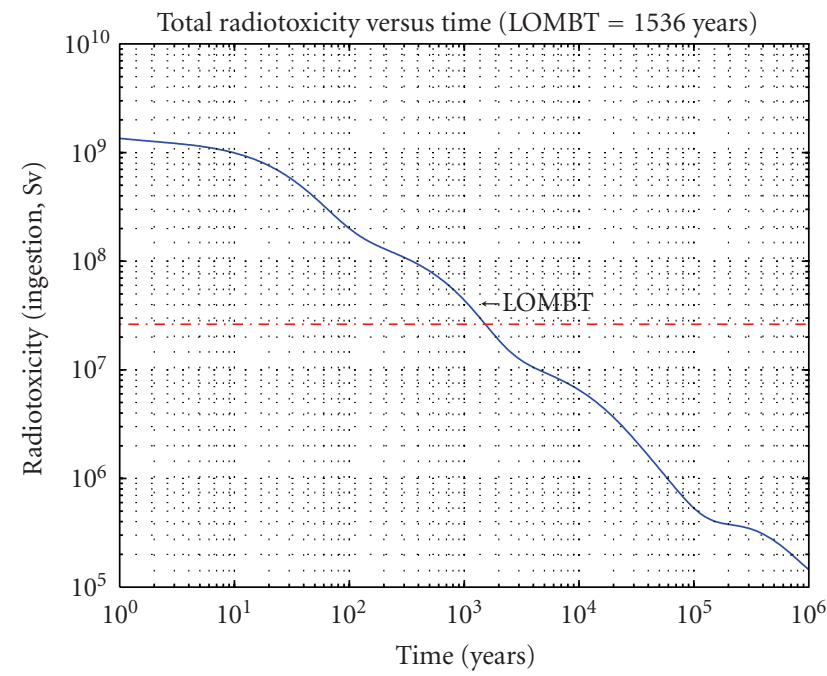

FIGURe 21: GCFR total radiotoxicity versus time (only $0.1 \% \mathrm{Pu}$ and Np left in waste).

Before concluding this paragraph, it is useful (mainly for complete scenario evaluations) to underline some further points (deeply analyzed in [27]).

(i) To perform a deeper scenario analysis, also for the waste evaluations (in terms of LOMBT, decay power trends, volumes, etc.) a more refined ratio among EPR, PBMR, and GCFR would have to be taken into account.

(ii) A better utilization of GCFR implies the adoption of a multiple recycling strategy in this kind of reactor; following this approach the final LOMBT could be reduced to $\sim 1 / 5$ of the value calculated in this research [27].

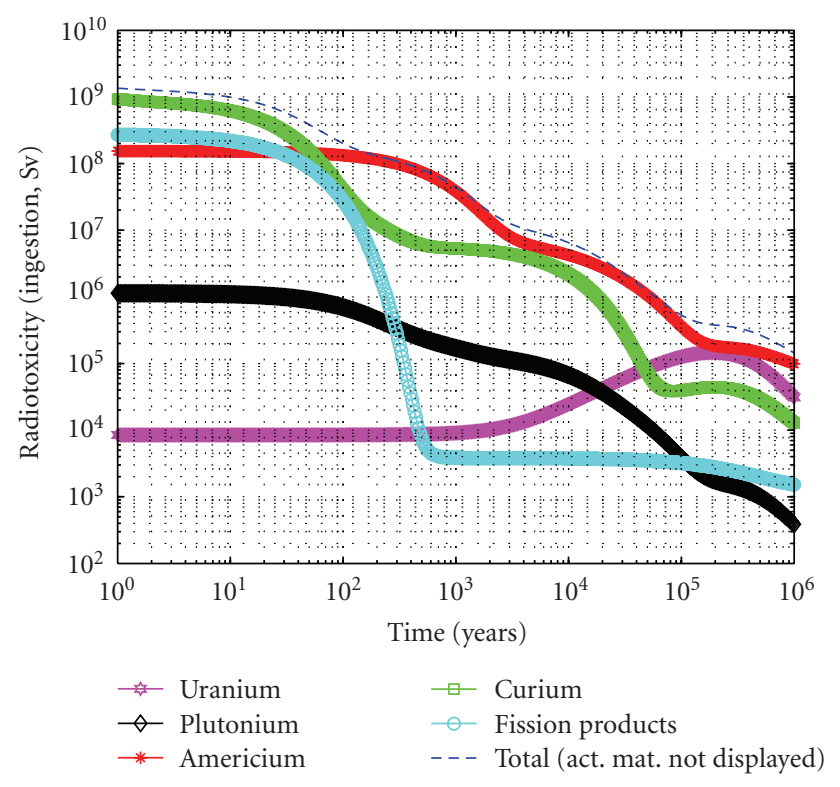

FIGURE 22: GCFR contribution of each element to the total radiotoxicity versus Time (only $0.1 \% \mathrm{Pu}$ and $\mathrm{Np}$ left in waste).

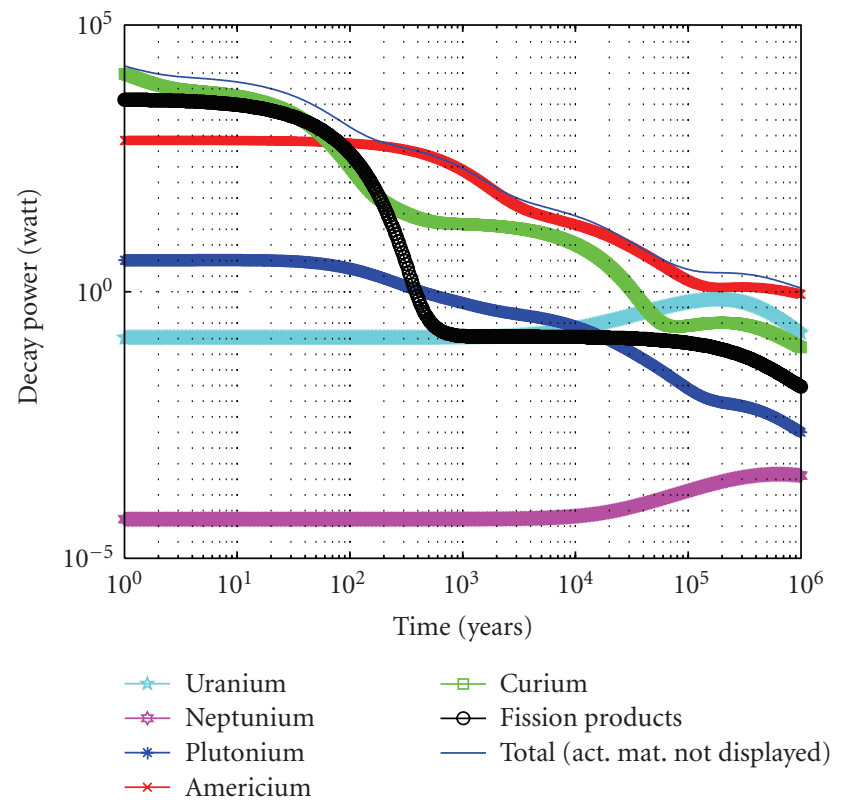

FIGURE 23: GCFR contribution of each element to the total Decay Power versus Time (only $0.1 \% \mathrm{Pu}$ and $\mathrm{Np}$ left in waste).

\section{Conclusions}

The scientific community is called to find a sustainable solution to guarantee the supply of future energy demand without compromising the environment integrity, complementary but fundamental target to achieve. Central role in this process lies with the nuclear energy production because it is the only source of energy capable of providing a large quantity of energy without relevant greenhouse gas releases. But a special regard has to be paid to the reduction of the 
TABLE 12: Energy produced by each reactor.

\begin{tabular}{lcccc}
\hline & EPR & PBMR & GCFR & Integrated cycle \\
\hline $\begin{array}{l}\text { Thermal } \\
\text { energy }\end{array}$ & 1490.16 & 190.96 & 18.92 & 1700.04 \\
$\begin{array}{l}\text { TWh/year] } \\
\begin{array}{l}\text { Electric } \\
\text { energy }\end{array}\end{array}$ & 529.62 & 91.84 & 9.08 & 630.54 \\
\hline TWh/year] & & & & \\
\hline
\end{tabular}

HLW inventory and to the optimization of the exploitation of the fuel resources.

Starting from these considerations, this work focused on the evaluation of possible advantages that a symbiotic cycle (EPR-PBMR-GCFR) could entail. The proposed cycle is considered in the frame of a general scenario analysis that takes into account also the resources availability. So the analyses have been carried out with the purposes of:

(i) maximizing the fuel exploitation by recycling part of the waste,

(ii) minimizing the long-term spent fuel radiotoxicity,

(iii) having a look at the waste decay heat evolution, in order to allow a safe storage for a long period of time.

Regarding the fuel exploitation, the use of a symbiotic fuel cycle allows to obtain a total electric energy equal to $630.54 \mathrm{TWh} /$ year (instead of only $529.62 \mathrm{TWh} /$ year) without consuming additional raw materials.

Regarding the waste radiotoxicity, from the obtained results it could be deduced that

(i) the use of PBMR reduces the LOMBT from $\sim 170000$ (value for EPR waste) to $\sim 70100$ years, in the case of direct disposal of pebble, or to $\sim 3100$ years, if $\mathrm{Pu}$ and $\mathrm{Np}$ are separated ( $0.1 \%$ left in waste);

(ii) the use of GCFR further reduces the LOMBT from $\sim 3100$ (EPR+PBMR) to $\sim 1500$ years, than, of course, the $\mathrm{Pu}$ and the $\mathrm{Np}$ are separated in order to be reused as fuel in subsequent irradiation steps. In fact, the implementation of a multiple recycling strategy in GCFR could further reduce the LOMBT to values $\sim 1 / 5$ of the calculated one [27].

Another important topic is the decay heat evolution. In this frame it should be noted that, as expected, the major contribution arises from the $\mathrm{Pu}$ isotopes. In addition it should be noted that the worst trend can be found for the PBMR waste (mainly due to the total quantity of $\mathrm{Pu}$ in the spent fuel and to its isotopic vector).

The obtained results have to be considered just as a (very) preliminary evaluation of a symbiotic EPR-PBMR-GCFR fuel cycle, useful as a first step to be completed (performing more detailed calculations, too) and implemented also by means of dedicated scenario codes in a more general analysis.

In order to perform these deeper evaluations, other key points (e.g., environmental and economic aspects, waste volumes comparison, $U$ consumption estimation, etc.) have to be taken into account. In addition, to perform a more realistic scenario analysis, also for the waste evaluations (in terms of LOMBT, decay power trends, volumes, etc.), a refined ratio among EPR, PBMR, and GCFR would have to be taken into account. In the frame of an analysis of a sustainable fuel cycle, it will be also important, in order to better characterize the fast reactor, to evaluate the Breeding Gain (BG) reached at the end of cycle.

Finally as further future works, it would be necessary to have a look to the real possibilities of technological implementations of the proposed fuel cycles (e.g., material technology, evaluation of the reprocessing processes on an industrial scale, etc.).

\section{Abbreviations}

BOC: $\quad$ Begin of cycle

CCS: $\quad$ Carbon capture and sequestration

CDF: Core damage frequency

DU: $\quad$ Depleted uranium

EFPD: $\quad$ Effective full power days

EOC: $\quad$ End of cycle

EPR: $\quad$ European pressurized reactor

ESF: $\quad$ Emergency safety features

EU: $\quad$ European union

GCFR: Gas cooled fast reactor

GHG: Greenhouse gas

HLW: $\quad$ High level waste

HM: Heavy metal

HTR: High temperature reactor

HTTR: High temperature engineering test reactor

IAEA: International Atomic Energy Agency

IEA: International Energy Agency

IPCC: Intergovernmental panel on climate change

IR: $\quad$ Inferred resources

MA: $\quad$ Minor actinides

NEA: $\quad$ Nuclear Energy Agency

P\&T: $\quad$ Partitioning \& transmutation

PUMA: Plutonium and minor actinides management in thermal high temperature reactors

RAPHAEL: ReActor for process heat, hydrogen, and eLectricity generation

RAR: $\quad$ Reasonable assured resources

SNE: TPSustainable nuclear energy—technical platform

TRISOT: ristructural-isotropic

USD: $\quad$ Unites States Dollar

\section{Acknowledgments}

The work presented in this paper was partly funded by the European Union Sixth Framework Program, under Contracts PuMA, GCFR, and RAPHAEL. First of all, The authors want to thank Dr. Bomboni of DIMNP for her strong support and Dr. Bufalino of SORIT for his precious suggestions and help. Finally they like to thank Dr. Mitchell of AMEC-NNC, Dr. Kuijper and Dr. van Heek both of NRG, Professor Kloosterman of TUD, and Dr. von Lensa of FZJ for the collaboration. 


\section{References}

[1] NEA, "Nuclear energy outlook," Tech. Rep., Organisation for Economic Co-operation and Development, 2008.

[2] G. Nerac, "A technology roadmap for generation IV nuclear energy systems," Tech. Rep. GIF-002-00, Department of Energy, Washington, DC, USA, 2002.

[3] IAEA, "Energy, electricity and nuclear power: developments and projections," Tech. Rep. STI/PUB/1304, 2007.

[4] IPCC, "Emissions scenarios," Tech. Rep., Specification Representation Associates, 2000.

[5] IEA, "Energy technology perspectives," Tech. Rep., Organisation for Economic Co-operation and Development, 2008.

[6] EU Parliament, "Report on conventional energy sources and energy technology," Tech. Rep. A6-0348/2007, 2007.

[7] IEA, "World energy outlook," Tech. Rep., Organisation for Economic Co-operation and Development, 2008.

[8] NEA, "Risks and benefits of nuclear energy," Tech. Rep. 6242, Organisation for Economic Co-operation and Development, 2007.

[9] EWG, "Uranium resources and nuclear energy," Tech. Rep. 1/06, 2006.

[10] NEA, "Uranium 2007: resources, production and demand," Tech. Rep. 6345, Organisation for Economic Co-operation and Development, 2008.

[11] IEA, "World energy outlook," Tech. Rep., Organisation for Economic Co-operation and Development, 2006.

[12] IAEA, "Energy, electricity and nuclear power estimates for the period up to 2030," Tech. Rep. IAEA-RDS-1/28, 2008.

[13] EUROSTAT, "Electricity Statistics-provisional data for 2007," EU.

[14] EC, "Report on strategy study on LWR/HTR symbiosis," Tech. Rep. HTR-N1-04708-D3.3.1, 2004.

[15] G. Lomonaco, Problematiche di sicurezza nella produzione di idrogeno mediante impianti HTR, Bachelor Degree Thesis, University of Pisa, Pisa, Italy, December 2003, http://www. tesionline.it/default/tesi.asp?idt=10361.

[16] N. Cerullo, D. Bufalino, G. Forasassi, G. Lomonaco, P. Rocchi, and V. Romanello, "The capabilities of HTRs to burn actinides and to optimize plutonium exploitation," in Proceedings of the 12th International Conference on Nuclear Engineering (ICONE12), vol. 1, pp. 495-501, Arlington, Va, USA, April 2004.

[17] N. Cerullo, D. Bufalino, G. Forasassi, G. Lomonaco, P. Rocchi, and V. Romanello, "An additional performance of HTRs: the waste raditoxicity minimization," Radiation Protection Dosimetry, vol. 115, no. 1-4, pp. 122-125, 2005.

[18] E. Bomboni, N. Cerullo, G. Lomonaco, and V. Romanello, "A critical review of the recent improvements in minimizing nuclear waste by innovative gas-cooled reactors," Science and Technology of Nuclear Installations, vol. 2008, Article ID 265430, 18 pages, 2008.

[19] AREVA-NP, “UK-EPR, fundamental safety overview," Tech. Rep., 2008.

[20] E. Fridman, E. Shwageraus, and A. Galperin, "Implementation of multi-group cross-section methodology in BGCore MCdepletion code," in Proceedings of the International Conference on the Physics of Reactors (PHYSOR '08), Interlaken, Switzerland, September 2008.

[21] EC, "FP5-EAECTP C called also HTR-N1,” Tech. Rep. FIKICT-2001-00169, European Commission, 2001-2005.

[22] EC, "PUMA - plutonium and minor actinides management in thermal high temperature reactors," EC, 2006-2009.
[23] EC, "ReActor for process heat, hydrogen and eLectricity generation," EC, 2006-2009.

[24] EC, "Sustainable nuclear energy technical platformml: strategic research agenda," Final Draft, 2009.

[25] N. Fujimoto, S. Fujikawa, H. Hayashi, et al., "Present status of HTTR project-achievement of $950^{\circ} \mathrm{C}$ reactor outlet coolant temperature," in Proceedings of the IAEA 2nd International Topical Meeting on HTR Technology, International Atomic Energy Agency, Beijing, China, September 2004.

[26] Y. Xu, "The HTR-10 project and its further development," in Proceedings of the IAEA Conference on Humboldt-Table RockSteinauer (HTR '02), International Atomic Energy Agency, Petten, The Netherlands, April 2002.

[27] E. Bomboni, N. Cerullo, and G. Lomonaco, "Assessment of LWR-HTR-GCFR integrated cycle," Science and Technology of Nuclear Installations, vol. 2009, Article ID 193594, 14 pages, 2009.

[28] E. Bomboni, N. Cerullo, and G. Lomonaco, "New developments in actinides burning with symbiotic LWR-HTR-GCFR fuel cycles: perspectives and challenges," in Proceedings of the 10th International Exchange Meeting on Partitioning and Transmutation (IEMPT '08), vol. 10, Mito, Japan, October 2008. 

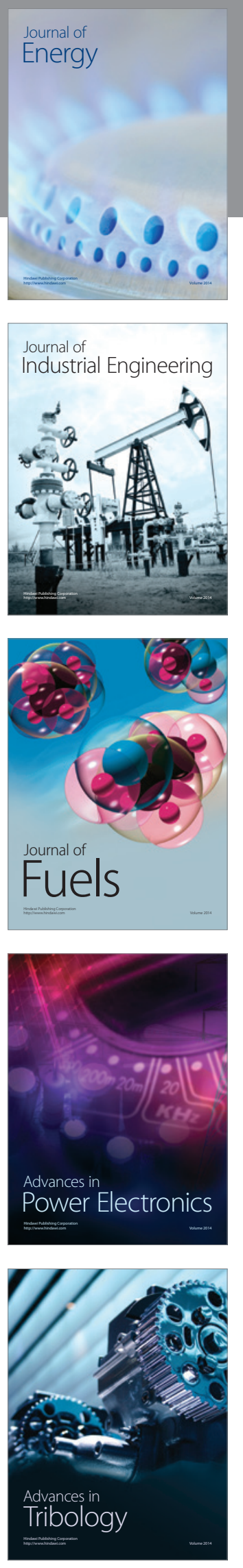
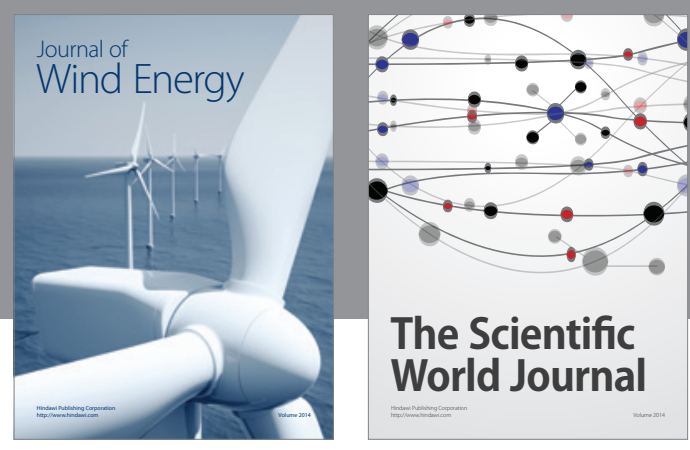

The Scientific World Journal

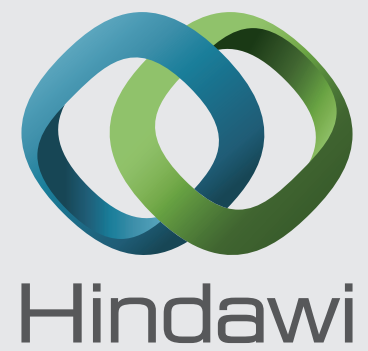

Submit your manuscripts at http://www.hindawi.com
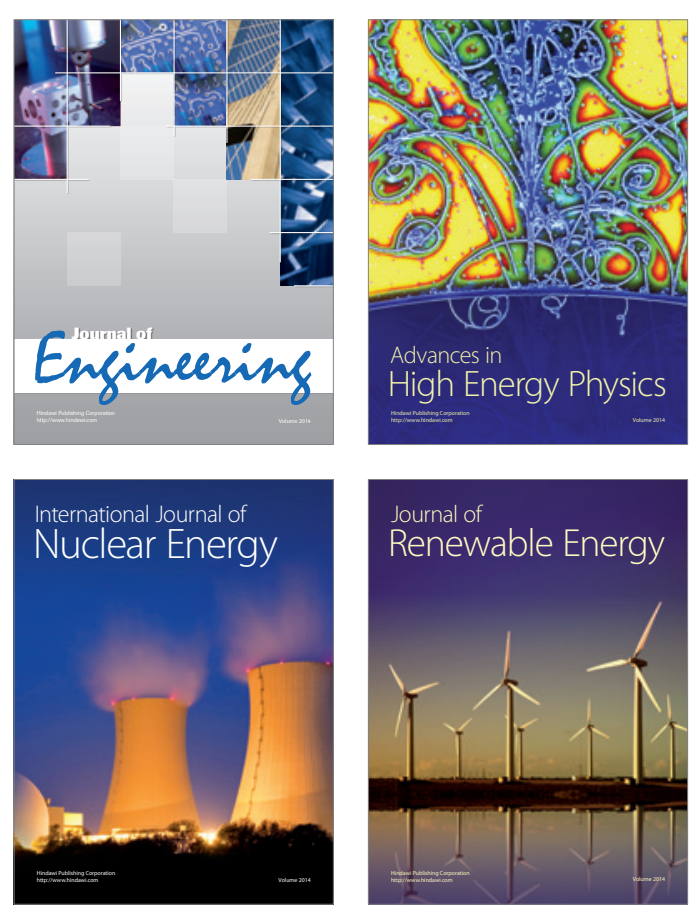

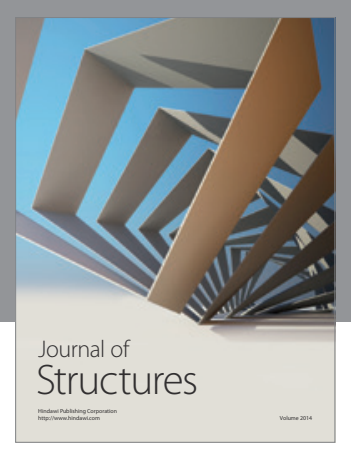

Rotating
Mechinery
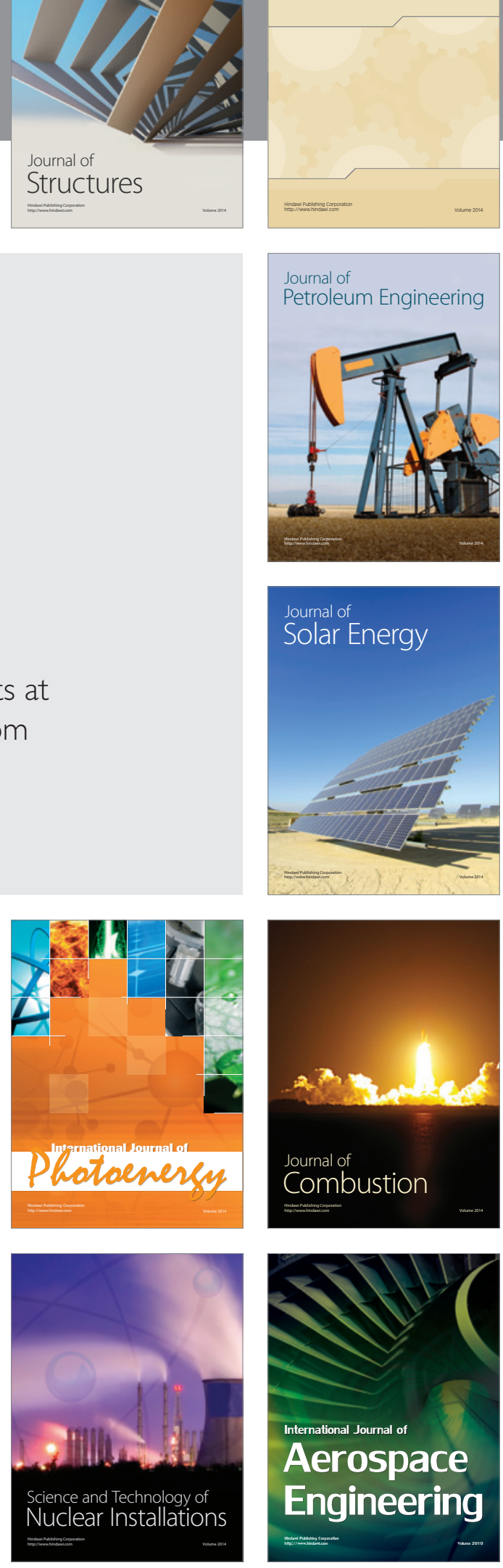